\title{
The ambiguous life of Dientamoeba fragilis: the need to investigate current hypotheses on transmission
}

\author{
JOEL L. N. BARRATT ${ }^{1,2,3}$, JOHN HARKNESS ${ }^{1,3}$, DEBORAH MARRIOTT ${ }^{1,3}$, \\ JOHN T. ELLIS ${ }^{2,3}$ and DAMIEN STARK ${ }^{1,2} *$ \\ ${ }^{1}$ Division of Microbiology, SydPath, St Vincent's Hospital, Darlinghurst, Australia \\ ${ }^{2}$ University of Technology Sydney, i3 Institute, Broadway, Australia \\ ${ }^{3}$ University of Technology Sydney, Department of Medical and Molecular Biosciences, Broadway, Australia \\ (Received 15 September 2010; revised 11 October and 22 November 2010; accepted 28 November 2010; first published online 24 February 2011)
}

\section{SUMMARY}

Dientamoeba fragilis is an inhabitant of the human bowel and is associated with gastrointestinal illness. Despite its discovery over a century ago, the details of Dientamoeba's life cycle are unclear and its mode of transmission is unknown. Several theories exist which attempt to explain how Dientamoeba may be transmitted. One theory suggests that animals are responsible for the transmission of Dientamoeba. However, reports of Dientamoeba in animals are sporadic and most are not supported by molecular evidence. Another theory suggests that Dientamoeba may be transmitted via the ova of a helminth. Given that the closest relative of Dientamoeba is transmitted via the ova of a helminth, this theory seems plausible. It has also been suggested that Dientamoeba could be transmitted directly between humans. This theory also seems plausible given that other relatives of Dientamoeba are transmitted in this way. Despite numerous investigations, Dientamoeba's mode of transmission remains unknown. This review discusses the strengths and weaknesses of theories relating to Dientamoeba's mode of transmission and, by doing so, indicates where gaps in current knowledge exist. Where information is lacking, suggestions are made as to how future research could improve our knowledge on the life cycle of Dientamoeba.

Key words: Dientamoeba fragilis, animals, Histomonas, Tritrichomonas, transmission, Enterobius vermicularis.

\section{INTRODUCTION}

Dientamoeba fragilis is a trichomonad parasite of the human gastrointestinal tract that is associated with gastrointestinal disease (Stark et al. 2009b, 2010b). Despite its discovery over a century ago, the life cycle of Dientamoeba is not understood (Fig. 1). The only known stage in the life cycle of Dientamoeba is the trophozoite, which is extremely fragile once passed from the host. No environmentally resistant cyst stage has been identified. While it is possible that Dientamoeba trophozoites are transmitted directly from host to host, the fragile nature of the trophozoite stage has led some researchers to suggest that this mode of transmission is unlikely (Yang and Scholten, 1977). Consequently, several theories have emerged which attempt to explain how Dientamoeba trophozoites could survive outside their host for a sufficient period to allow their transmission. One possibility is that Dientamoeba is transmitted via the ova of a helminth. Another possibility is that a resistant cyst stage exists for Dientamoeba though remains undiscovered.

* Corresponding author: Department of Microbiology, St Vincent's Hospital, Victoria Street, Darlinghurst 2010, NSW, Australia. Tel: +6128382 9196. Fax: +6128382 2989. E-mail: dstark@stvincents.com.au
Unfortunately, none of these theories has been sufficiently proven.

In the initial description of Dientamoeba, Jepps and Dobell (1918) commented on the fragile nature of the trophozoite stage though were unable to identify a cyst stage in the stools of infected human subjects. Subsequently, these authors theorized that Dientamoeba may produce cysts in an unidentified species of animal (Jepps and Dobell, 1918). While no cyst stage has been identified in humans or animals, several species of animal are reported to carry Dientamoeba (Knowles and DasGupta, 1936; Dobell, 1940; Noble and Noble, 1952; Myers and Kuntz, 1968; Crotti et al. 2007; Stark et al. 2008; Lankester et al. 2010).

Following the initial description of Dientamoeba (Jepps and Dobell, 1918) several authors described what appeared to be cysts, pseudocysts or cyst-like stages of Dientamoeba (Kofoid, 1923; Greenway, 1928; Wenrich, 1936; Knoll and Howell, 1945; Piekarski, 1948; Silard et al. 1979). However, these apparent cyst-like forms were found to be degenerate trophozoites or their true identity could not be confirmed (Johnson et al. 2004). Despite the relatively high incidence of $D$. fragilis infection reported in recent studies (Millet et al. 1983b; Girginkardesler et al. 2003; Bruijnesteijn van Coppenraet et al. 2009; 


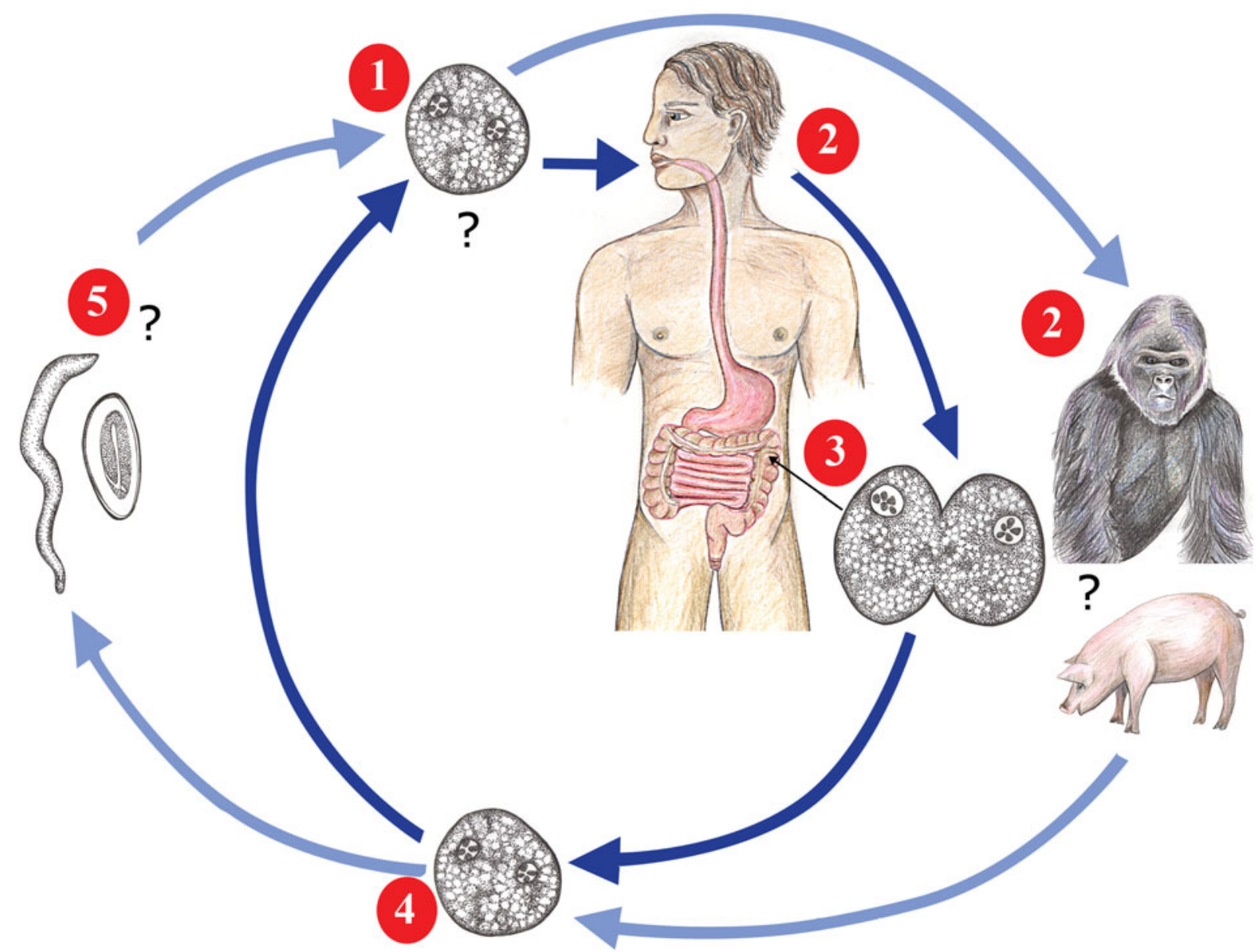

Fig. 1. The proposed life cycle of Dientamoeba fragilis. Dientamoeba trophozoites (or an undiscovered transmissible stage) are ingested from the external environment by a host species (1). Humans are thought to be the preferred host of Dientamoeba, though gorillas, pigs, sheep and other primate species may also be potential hosts (2). Once ingested, Dientamoeba travels to the large intestine where it multiplies by binary fission (3). Dientamoeba organisms are then passed into the environment in the faeces (4) where they contaminate food and/or water sources. Dientamoeba is then ingested by a new host, completing the cycle. Some authors propose that; due to the fragile nature of Dientamoeba trophozoites outside their host and the apparent lack of a cyst stage, it is unlikely that Dientamoeba can infect humans directly. It has been suggested that Dientamoeba may be transmitted in the ova of the helminth; Enterobius vermicularis (5) though the role of Enterobius in the life cycle of Dientamoeba is controversial.

Schuster and Jackson, 2009), a cyst stage has not been reported. It is now generally accepted that $D$. fragilis does not have a cyst stage (Johnson et al. 2004).

Dobell (1940) was the first to postulate that Dientamoeba may be transmitted in the ova of a helminth. This theory was based on Dientamoeba's similarity to Histomonas meleagridis which is transmitted in the ova of the poultry helminth Heterakis gallinarum. While several authors provide support for this theory (Burrows and Swerdlow, 1956; Ockert, 1972a,b, 1975; Ockert and Schmidt, 1976; Yang and Scholten, 1977; Girginkardesler et al. 2008), other researchers report no association between helminths and Dientamoeba (Vandenberg et al. 2006; Stark et al. 2010b). As such, the role of helminths in the transmission of Dientamoeba remains a matter of debate.

According to phylogenetic studies Dientamoeba, H. meleagridis and Parahistomonas wenrichi share a recent common ancestor with members of the genus Tritrichomonas (Gerbod et al. 2001, 2002; Ohkuma et al. 2005) (Fig. 2). The life cycles of Histomonas, Parahistomonas and Tritrichomonas spp. are generally well characterized and it is postulated that the lives of these species' could provide some clues as to how Dientamoeba is transmitted. However, the lives of Histomonas, Parahistomonas and Tritrichomonas are quite different. Histomonas and Parahistomonas are gastrointestinal parasites of poultry (Levine, 1985; McDougald, 2005) while members of the genus Tritrichomonas include a sexually transmitted pathogen of cattle (Felleisen et al. 1998), the aetiological agent of a feline diarrhoeal disease (Levy et al. 2003; Corbeil et al. 2008), and parasites of the porcine (Tachezy et al. 2002), simian (Culberson et al. 1986), reptilian and amphibian (Borges et al. 2004) gut. Despite the apparent differences between the life cycles of these organisms, similarities do exist which 


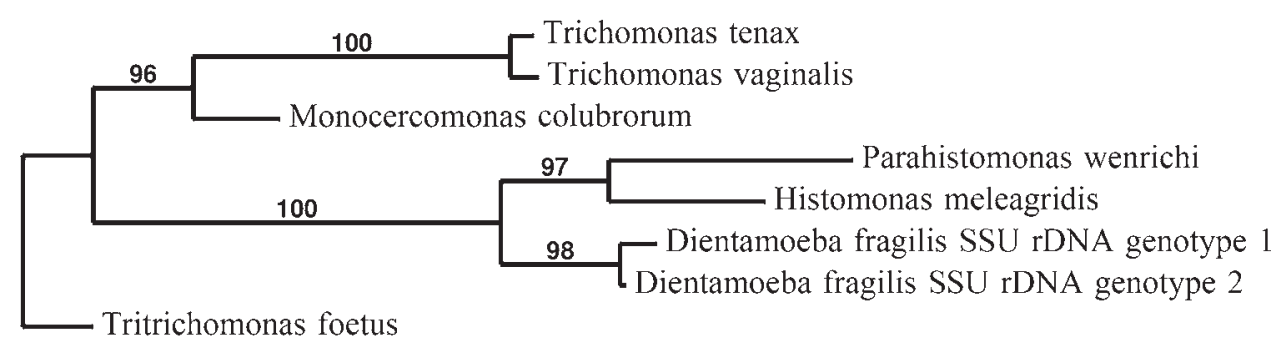

0.05

Fig. 2. Phylogenetic tree showing the relative phylogenetic positions of Dientamoeba fragilis genotype 1 (GenBank Accession: AY730405.1), Dientamoeba fragilis genotype 2 (U37461.1), Histomonas meleagridis (AJ920323.1), Parahistomonas wenrichi (EU647889.1) Tritrichomonas foetus (M81842.1), Monocercomonas colubrorum (AY319278.1), Trichomonas vaginalis (AY338475.1) and Trichomonas tenax (U37711.1) based on Small Subunit Ribosomal DNA ( $\mathrm{SSU}$ rDNA) sequences. Support values for branches are shown as a percentage. The length of the distance scale bar is equivalent to a sequence difference of $5 \%$. This tree was constructed using the software available on the website; www.phylogeny.fr/

may provide some insights into the life cycle of Dientamoeba.

This manuscript critically reviews the theories relating to Dientamoeba's transmission by discussing the strengths and weaknesses of each. Where gaps in current knowledge exist, suggestions are made on how future research could improve our understanding on the life cycle of Dientamoeba. Also, the life cycles of Histomonas, Parahistomonas and T. foetus are explored to identify similarities which may aid in the further characterization of Dientamoeba's life cycle.

\section{DIENTAMOEBA'S MODE OF TRANSMISSION IS UNKNOWN}

Based on the absence of a cyst stage and the fragility of Dientamoeba trophozoites once passed from their host, some researchers suggest that direct faecal oral transmission of Dientamoeba is unlikely (Yang and Scholten, 1977). Dientamoeba's mode of transmission presents a problem for parasitologists. Despite years of research all efforts to elucidate the details of Dientamoeba's life cycle have been mostly unsuccessful.

Attempts to infect humans with cultured D. fragilis trophozoites via the oral route failed (Dobell, 1940), suggesting that they do not survive the acidic conditions of the stomach. Furthermore, Dientamoeba trophozoites are reported to survive from 6 to $48 \mathrm{~h}$ after being passed from the host, which is too short a period to make transmission efficient (Kean and Malloch, 1966; Stark et al. 2010b). To complicate matters further, Dientamoeba trophozoites are said to burst when placed in boiled pond water (Wenrich, 1944) or tap water (Butler, 1996). This suggests that water sources contaminated with human faeces are unlikely to be a source of Dientamoeba infection. Furthermore, Dientamoeba trophozoites do not grow at ambient room temperature (Brug, 1938; Barratt et al. 2010), indicating that Dientamoeba is not a freeliving organism which infects humans opportunistically.

THE ROLE OF ANIMALS IN DIENTAMOEBA'S LIFE CYCLE

Animal hosts play an important role in the transmission of many enteric protozoa that infect humans (Schlundt et al. 2004; Smith et al. 2007; Pozio, 2008). Animal reservoirs are also a potential source of many human parasitic infections (Yoshikawa et al. 2003; Inpankaew et al. 2007; Robertson, 2009; Traub et al. 2009). As such, it is possible that animals are involved in the transmission of Dientamoeba. As few studies have explored this possibility, the role of animals remains uncertain. In most cases the finding of Dientamoeba in animals was incidental.

Knowles and Das Gupta (1936) detected Dientamoeba in the stools of captive macaques (1/30) using an iron haematoxylin staining technique. According to these authors, the organism was encountered in 'scanty numbers' and was of 'typical appearance' (Knowles and DasGupta, 1936). Hegner and Chu (1930) reported Dientamoeba infections in 2/44 wild monkeys from the Philippines. Myers and Kuntz (1968) detected $D$. fragilis in $<1 \%$ of captive baboons and $<2 \%$ of those trapped in the wild. Microscopic examination of stool samples was the method employed though the specific staining technique was not described (Myers and Kuntz, 1968). Stark et al. (2008) identified Dientamoeba in the stools of 3 western lowland gorillas using an iron haemotoxylin staining technique and confirmed these results by PCR. More recently, Lankester et al. (2010) described a case of irritable bowel-like disease in a western lowland gorilla. The illness described by Lankester (2010) was later attributed to Dientamoeba 
by identification of trophozoites in faecal smears stained with a Field's stain.

Noble and Noble (1952) observed D. fragilis trophozoites in stained smears (haematoxylin and/or Giemsa stains) made from the stools of sheep though make no mention of the prevalence. In contrast, Stark et al. (2008) reported Dientamoeba infections in 0/50 sheep using an iron haematoxylin technique. Crotti et al. (2007) detected Dientamoeba trophozoites in the stools of 53/121 farmed pigs using a Giemsa staining technique. In contrast, Noble and Noble (1952) examined stools from 30 pigs and made no mention of $D$. fragilis in these specimens. Similarly, Stark et al. (2008) found no evidence of $D$. fragilis in the stools of 135 swine. Interestingly, one study described contact with rabbits as a risk factor for Dientamoeba infection (Stensvold et al. 2009). However, Stark et al. (2008) examined the stools of 20 rabbits and did not detect D. fragilis.

Attempts to induce experimental infections in a range of animals have been unsuccessful (Mollari and Anzulovic, 1938; Dobell, 1940; Wenrich, 1944; Knoll and Howell, 1945; Kean and Malloch, 1966). Mollari and Anzulovic (1938) failed in their attempt to infect kittens with Dientamoeba. Dobell (1940) tried to infect 6 chicks by rectal inoculation of cultured Dientamoeba trophozoites. A transient infection was achieved in 1 chick though the infection was spontaneously cleared after 1 week. At the end of this experiment, the chick was sacrificed and examination of the caeca and liver revealed no pathological changes (Dobell, 1940). This author also tried to infect himself and 2 macaques orally with cultured Dientamoeba trophozoites though without success. Efforts made to infect 1 of these macaques with cultured Dientamoeba trophozoites via rectal injection also failed (Dobell, 1940).

Wenrich (1944) tried to infect laboratory rats with cultured Dientamoeba trophozoites orally and via rectal injection, also without success. Knoll and Howell (1945) were unable to infect kittens with cultured Dientamoeba trophozoites via rectal injection and the oral route. According to Knoll and Howell (1945), no Dientamoeba trophozoites were recovered at autopsy and no gross pathological changes in the gastrointestinal tract were noted. Knoll and Howell (1945) also examined the entrails of 12 laboratory rats obtained from an unrelated study and found no trace of Dientamoeba infection. Attempts were also made by Kean and Malloch (1966) to infect laboratory rats. Apparently, preliminary observations showed that Dientamoeba does 'attach to the caecal mucosa and cause damage to the underlying cells' and, 'oedema of the mucosa [was] evident, but actual ulceration [had] not yet been produced' (Kean and Malloch, 1966). However, no later reference was made pertaining to these experiments (Kean and Malloch, 1966). Studies that report the finding of Dientamoeba in animals are summarized in Table 1 .
THE ROLE OF HELMINTHS IN THE TRANSMISSION OF DIENTAMOEBA

It was originally postulated by Dobell (1940) that $D$. fragilis could be transmitted via the ova of a nematode such as Trichuris trichuria or Ascaris lubricoides. This was based on Dientamoeba's similarity to Histomonas and a noted association between Dientamoeba and helminth infections (Dobell, 1940). Burrows and Swerdlow (1956) were the first to propose that Enterobius vermicularis (pinworm) was the probable vector of Dientamoeba and described what appeared to be Dientamoeba trophozoites in the ova of E. vermicularis. Several years later, Ockert and coworkers published a series of reports which supported the opinion that $D$. fragilis was transmitted in the ova of E. vermicularis (Ockert, 1972a, b, 1975; Ockert and Schmidt, 1976). Ockert claimed that he had infected himself and 2 other subjects with Dientamoeba using pinworm eggs derived from a boy who was infected with both pinworm and Dientamoeba (Ockert, 1972b; Ockert, 1975). Isoelectric studies performed by Ockert and Schmidt (1976) showed that the nuclei and cytoplasm of amoeboid bodies which occurred in Enterobius ova and trophozoites of Dientamoeba from culture had almost identical isoelectric points (Ockert and Schmidt, 1976; Johnson et al. 2004). In a later study, Yang and Scholten (1977) noted a strong association between $D$. fragilis infections and infections with $E$. vermicularis in a large survey examining 43000 individuals. Girginkardesler et al. (2008) recently reported a relationship between the incidence of Dientamoeba and Enterobius infections. Interestingly, Sukanahaketu (1977) also identified Dientamoeba-like structures within the ova of A. lumbricoides isolated from the stools of subjects with mixed infections of Dientamoeba and Ascaris.

In contrast, several studies found no relationship between Dientamoeba and E. vermicularis (Kean and Malloch, 1966; Walker et al. 1985; Oxner et al. 1987; Cuffari et al. 1998; Menghi et al. 2005; Stark et al. 2006, 2009a, 2010b). In the study by Kean and Malloch (1966), only 2/100 patients with pure Dientamoeba infections had a history of pinworm infection. A study performed in the Sydney suburb of French's Forest found that only 2/125 subjects had E. vermicularis ova in their stools while $21 / 125$ were infected with Dientamoeba. The authors noted, however, that the prevalence of $E$. vermicularis in this group could have been under-represented as only stools were examined and E. vermicularis ova are rarely observed in stools (Walker et al. 1985). In a study performed at Christchurch Hospital Microbiology department (New Zealand) (Oxner et al. 1987) the incidence of $D$. fragilis was $41 / 1350(3 \%)$. At the same time, the incidence of helminth infections was only 1/1350 (Oxner et al. 1987). In another study, DNA extracted from E. vermicularis ova derived 
Table 1. Studies that report the finding of Dientamoeba in animals

\begin{tabular}{|c|c|c|c|}
\hline Reference & Animal species examined (no. of animals) & $\begin{array}{l}\text { Dientamoeba detected? } \\
\text { Yes/No (\% prevalence) }\end{array}$ & Technique employed* \\
\hline $\begin{array}{l}\text { Hegner and } \\
\text { Chu (1930) }\end{array}$ & Wild monkeys from the Philippines - Macacus philipinensis (44) & Yes $(4 \cdot 5 \%)$ & Iron-haematoxylin staining technique \\
\hline $\begin{array}{l}\text { Knowles and } \\
\text { DasGupta } \\
\text { (1936) }\end{array}$ & Captive macaques (31) & Yes $(3 \cdot 2 \%)$ & Heidenhains' iron haematoxylin technique \\
\hline $\begin{array}{l}\text { Noble and } \\
\text { Noble (1952) }\end{array}$ & Bovine (34), Goat (28), Pig (30). & No & $\begin{array}{l}\text { Usually a Heidenhain's haematoxylin stain though } \\
\text { sometimes a Harris' haematoxylin stain, Giemsa } \\
\text { stain and/or Lugol's iodine stain }\end{array}$ \\
\hline $\begin{array}{l}\text { Noble and } \\
\text { Noble (1952) }\end{array}$ & Sheep (25) & $\begin{array}{l}\text { Yes (exact incidence } \\
\text { not disclosed) }\end{array}$ & $\begin{array}{l}\text { Usually a Heidenhain's haematoxylin stain though } \\
\text { sometimes a Harris' haematoxylin stain, Giemsa } \\
\text { stain and/or Lugol's iodine stain }\end{array}$ \\
\hline $\begin{array}{l}\text { Noble and } \\
\text { Noble (1952) }\end{array}$ & White laboratory rats (12) & No & $\begin{array}{l}\text { Rats were sacrificed and direct smears and cultures } \\
\text { were made from the contents and walls of the } \\
\text { caecum and large intestine }\end{array}$ \\
\hline $\begin{array}{l}\text { Noble and } \\
\text { Noble (1952) }\end{array}$ & An undisclosed number of dogs, kittens and laboratory rats & No & Techniques employed not disclosed \\
\hline $\begin{array}{l}\text { Myers and } \\
\text { Kuntz (1968) }\end{array}$ & Baboon - Papio doguera (49) & Yes $(2 \%)$ & $\begin{array}{l}\text { MIFC concentration technique - The staining } \\
\text { technique used was not disclosed }\end{array}$ \\
\hline $\begin{array}{l}\text { Crotti et al. } \\
(2007)\end{array}$ & Swine (121) & Yes $(43 \cdot 8 \%)$ & Giemsa-stained smears \\
\hline $\begin{array}{l}\text { Stark et al. } \\
(2008)\end{array}$ & $\begin{array}{l}\text { Bovine (50), horse (25), goat (25), swine (135), sheep (50), } \\
\text { chimpanzee (19), De Brazza's monkey (2), Francois' leaf monkey (2), } \\
\text { orang-utan (4), Red faced spider monkey (8), several bird } \\
\text { species including several Australian native species, chickens and ducks } \\
\text { ( } 78 \text { ), bush rat (2), domestic mouse (25), black rat (25), dog (50), cat (50), } \\
\text { large flying fox (6), guinea pig (20), rabbit (20), fat tailed dunnart (1). }\end{array}$ & No & Modified iron haematoxylin stain \\
\hline $\begin{array}{l}\text { Stark et al. } \\
(2008)\end{array}$ & Western lowland gorilla (10) & Yes $(30 \%)$ & Modified iron haematoxylin stain/PCR \\
\hline $\begin{array}{l}\text { Lankester et al. } \\
(2010)\end{array}$ & Western lowland gorilla (1) & Yes (N/A) & Field's stained faecal smears \\
\hline
\end{tabular}

* The diagnostic technique employed is important to note due to differences in sensitivity and specificity. Usually, molecular techniques such as PCR are more sensitive and specific than light microscopy (Stark et al. 2010a). 
from people infected with $D$. fragilis failed to produce a PCR product using Dientamoeba specific primers (Menghi et al. 2005). Stark et al. (2009a) found no current pinworm infection in D. fragilis-infected patients in 2 unrelated families from Sydney, Australia. Stark et al. (2010b) also found no coinfections with Dientamoeba and any helminth in a group of 19 patients infected with Dientamoeba.

THE LIFE CYCLES OF HISTOMONAS, PARAHISTOMONAS AND TRITRICHOMONAS

According to phylogenetic studies, the closest relatives of Dientamoeba include Histomonas, Parahistomonas and members of the genus Tritrichomonas (Gerbod et al. 2001, 2002; Ohkuma et al. 2005; Mantini et al. 2009). A simple phylogenetic tree constructed for the purposes of this discussion summarizes these relationships (Fig. 2). While the lives of these related trichomonads seem quite different, some similarities do exist which appear to be inherent in members of this group. It is postulated that these similarities may provide some information on the life cycle of Dientamoeba.

\section{Tritrichomonas foetus}

Members of the genus Tritrichomonas infect a broad range of animals including reptiles, mammals and birds. The most important member of the genus Tritrichomonas is Tritrichomonas foetus due to its economic significance in the cattle-raising industries. As such, T. foetus will be discussed here as a representative of the genus Tritrichomonas.

Tritrichomonas foetus has a broad host range though is best known as a sexually transmitted pathogen of cattle (Felleisen et al. 1998). However, based on recent reports the host range of $T$. foetus has expanded to include other animals.

Until recently, Pentatrichomonas hominis was considered to be the cause of a diarrhoeal disease in cats (Gookin et al. 1999; Romatowski, 2000; Levy et al. 2003). However, later reports utilizing DNA sequence analysis, DNA restriction analysis and electron microscopy confirmed that the aetiological agent was actually $T$. foetus (Levy et al. 2003; Tolbert and Gookin, 2009). However, experimental infections in cows have demonstrated that $T$. foetus isolates derived from cats induce a similar yet slightly different disease in cows when compared to T. foetus isolates derived from cattle (Stockdale et al. 2007). Similarly, T. foetus isolates derived from cattle may be used to infect cats experimentally, though infectivity is reduced compared to isolates derived from cats (Stockdale et al. 2008). As such, these organisms probably represent different subtypes of the same species.

Based on molecular, biochemical and morphological evidence, Tritrichomonas suis was also found to be identical to T. foetus (Tachezy et al. 2002; Lun et al.
2005). Therefore $T$. foetus is now considered an inhabitant of the porcine gut and snout (Levine, 1985; Tachezy et al. 2002). However, Cobo et al. (2001) were unable to induce colonization of the genitourinary tract of 9 heifers with $T$. suis via vaginal inoculation. As with the $T$. foetus isolates derived from cats, it is possible that the organism known as $T$. suis is actually a different subtype of $T$. foetus which has adapted to specifically infect swine. Interestingly, phylogenetic studies based on ribosomal RNA genes suggest that Tritrichomonas mobilensis which was originally described in the Bolivian squirrel monkey (Culberson et al. 1986), is also synonymous with $T$. foetus and $T$. suis (Felleisen, 1997; Kleina et al. 2004).

Tritrichomonas foetus has also been isolated from the faeces of dogs with diarrhoea (Gookin et al. 2005). According to Levine (1985), T. foetus-like organisms have also been found in the genito-urinary tract and aborted foetuses of pigs, horses and roe deer. These reports could have important ramifications to the epidemiology and control of trichomoniasis. This is because interspecies transmission of $T$. foetus may become a future problem. The finding of a $T$. foetustype organism in non-human primates could also have implications for human health. However, given the failure to establish a $T$. suis infection in cattle (Cobo et al. 2001) and the limited infectivity of cattle $T$. foetus isolates in cats (Stockdale et al. 2008), it is more likely that different strains or subtypes of $T$. foetus exist, each with a fairly restricted host range. Given the number of animals reported to carry T. foetus, it is possible that other animals may be identified as hosts of $T$. foetus in the future.

The life cycle of $T$. foetus is thought to involve 2 forms; a tear-shaped trophozoite form and a recently described pseudocyst form (Pereira-Neves and Benchimol, 2009). The T. foetus trophozoite is $10-25 \mu \mathrm{m}$ long and possesses 3 posterior flagella, 1 anterior flagellum and an undulating membrane (Levine, 1985). Trophozoites multiply asexually by binary fission (Levine, 1985).

Pseudocysts usually appear in response to unfavourable conditions though a small percentage of pseudocysts exist under normal conditions (Pereira-Neves et al. 2003). Pseudocysts occur when T. foetus trophozoites round up and internalize their flagella in response to various stimuli (Granger et al. 2000; Pereira-Neves et al. 2003; Mariante et al. 2004). This form lacks a protective cyst wall and does not represent a true cyst form (Granger et al. 2000). No true cyst stage exists (Levine, 1985).

In cattle, T. foetus is known as a cause of infertility and abortion (Felleisen et al. 1998) and infections are usually transferred during coitus. Infections may also be transferred to cows during gynaecological examinations or artificial insemination (Rae and Crews, 2006; Mardones et al. 2008). In bulls, infections are usually chronic and asymptomatic 


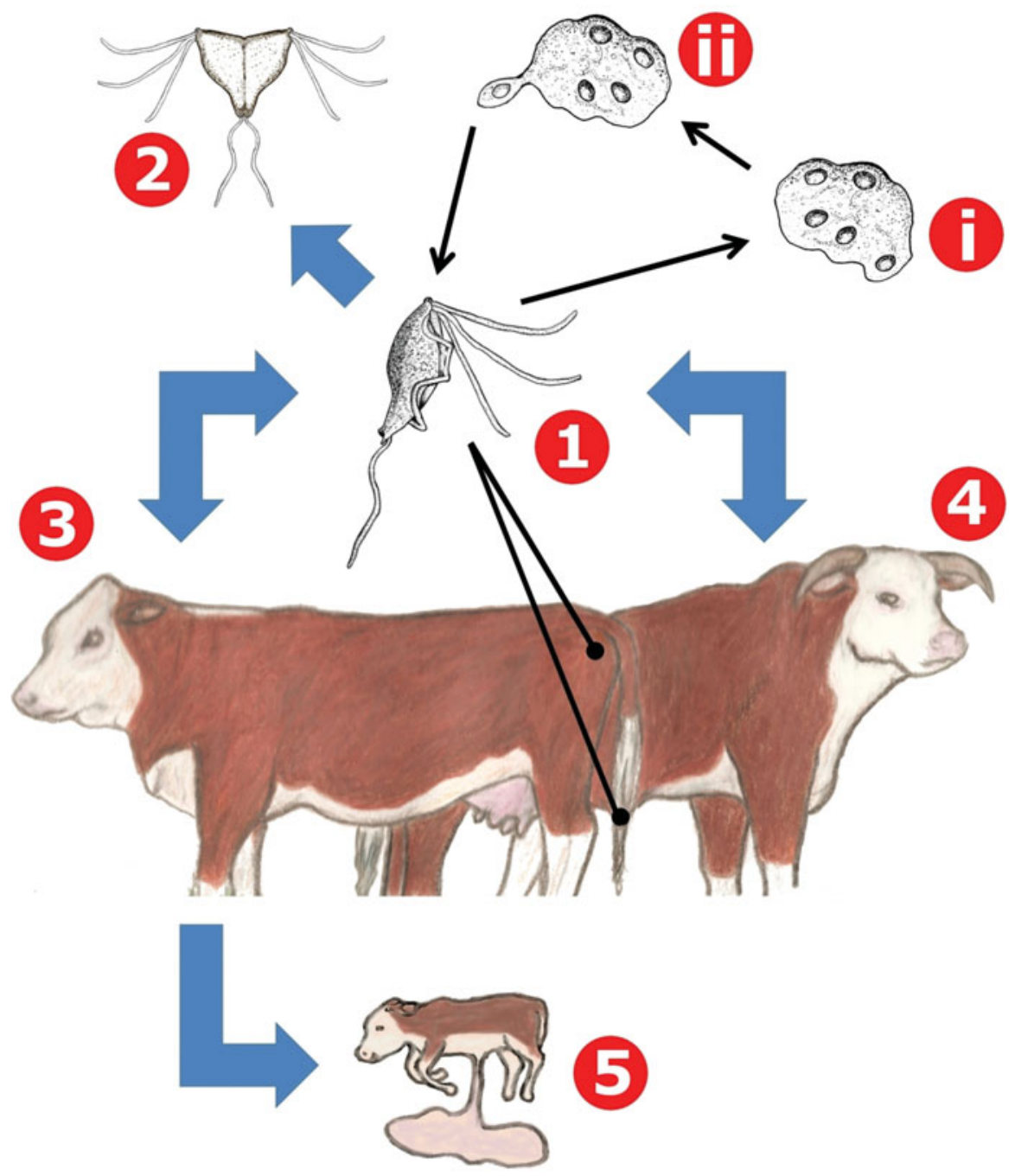

Fig. 3. The life cycle of Tritrichomonas foetus in cattle. Trophozoites of Tritrichomonas are transmitted between cows and bulls during coitus (1) and remain in the genito-urinary tract where they multiply by longitudinal binary fission (2). Under stress conditions trophozoites will internalize their flagella and replication of the nuclei and other cellular structures will occur, resulting in a multinucleated pseudocyst form (i). When conditions become desirable once more, mononucleate trophozoites will bud from the pseudocyst (ii). In bulls (4), infections are usually chronic and asymptomatic and often persist for the life of the animal. Infected cows (3) will initially experience vaginitis which may or may not resolve spontaneously. In some cases, endometritis can occur resulting in complete sterility. Tritrichomonas infections may also result in foetal loss during pregnancy (5).

(Mardones et al. 2008) and spontaneous recoveries are rare (Levine, 1985). There is no legal treatment for bovine trichomoniasis in several countries and as a result infected bulls are often slaughtered (Cobo et al. 2004, 2007; Agnew et al. 2008). Infected cows will experience vaginitis which may or may not resolve spontaneously. Infections which exist during pregnancy will often result in foetal loss. In some cases endometritis as a result of $T$. foetus infection can result in complete sterility (Levine, 1985) (Fig. 3).

Diagnosis of bovine trichomoniasis is often complicated by the presence of non-pathogenic T. foetuslike organisms (namely, Pentatrichomonas hominis and Tetratrichomonas spp.) in the genito-urinary tract of cattle (Cobo et al. 2004, 2007; Dufernez et al. 2007; Agnew et al. 2008; Huby-Chilton et al. 2009). It is postulated that the presence of these non-pathogenic organisms is most likely due to sodomy practiced amongst young bulls (BonDurant et al. 1999; Cobo et al. 2003, 2004). As such, it is recommended that PCR and culture techniques are employed in conjunction with light microscopy for an accurate diagnosis of bovine trichomoniasis (Campero et al. 2003; Hayes et al. 2003; Cobo et al. 2004).

In cats, $T$. foetus infection is acquired via ingestion of trophozoites from material contaminated with faeces. Trophozoites then travel to the intestines where they remain, inducing chronic diarrhoea (Holliday et al. 2009; Stockdale et al. 2009; Tolbert and Gookin, 2009). Tritrichomonas infections in cats show no preference in terms of breed or sex (Stockdale et al. 2009). Trophozoites are reported to remain culturally viable in cat faeces for up to $6 \mathrm{~h}$ after defecation (Hale et al. 2009) which allows 


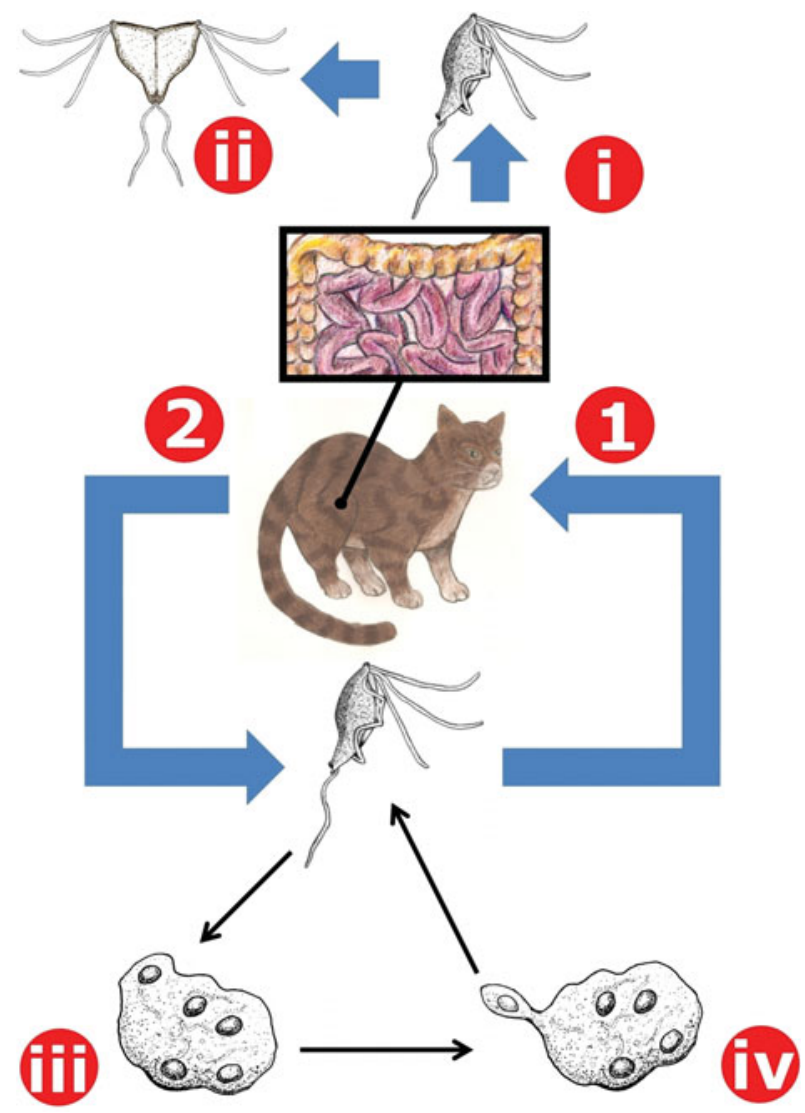

Fig. 4. The life cycle of Tritrichomonas foetus in cats. Tritrichomonas trophozoites are ingested by a feline host (1) and travel to its colon (i) where they multiply by longitudinal binary fission (ii). The presence of Tritrichomonas trophozoites in the colon induces chronic diarrhoea. Trophozoites are then passed in the faeces to the external environment (2) where they contaminate food and water sources of other potential hosts. Trophozoites of T. foetus are reported to survive for up to $6 \mathrm{~h}$ after being passed from the host. Under stress conditions trophozoites will internalize their flagella and replication of the nuclei and other cellular structures occurs, resulting in a multinucleated pseudocyst form (iii). When conditions become desirable once more, mononucleate trophozoites will bud from the pseudocyst (iv).

only a short period for re-infection to take place (Fig. 4).

Histomonas meleagridis and Parahistomonas wenrichi

Histomonas meleagridis is the closest known relative of $D$. fragilis and is the only species within the genus Histomonas. Histomonas infects a broad range of gallinaceous birds including chickens, pheasants, quails, guinea fowl and peafowl, although it is most renowned for its ability to decimate commercial turkey flocks resulting in huge economic losses (McDougald, 2005; Bleyen et al. 2009; Leberl et al. 2009). Compared to other gallinaceous production birds, turkeys are the most susceptible to histomoniasis (McDougald, 2005; Powell et al. 2009). The disease caused by Histomonas in turkeys is often referred to as 'blackhead disease' (McDougald, 2005).

Levine (1985) described 4 distinct stages within the Histomonas life cycle; a non-flagellated 'invasive stage', a non-flagellated 'vegetative stage', a nonflagellated 'resistant stage' and a flagellated 'caecal stage'. For the purposes of this manuscript, these 4 stages will be condensed into 2 stages; the flagellated caecal stage and the amoeboid tissue stage which comprises the 3 non-flagellated stages described by Levine (1985). The spherical non-flagellated stage is between 8 and $21 \mu \mathrm{m}$ in diameter. The caecal stage is spherical, between 5 and $30 \mu \mathrm{m}$ in diameter and has a single flagellum. The early invasive stage and the caecal stage both possess active pseudopodia and multiply by binary fission (Levine, 1985; Mielewczik et al. 2008; Munsch et al. 2009a).

Transmission of $H$. meleagridis is known to occur via 2 routes. Firstly and most simply, the flagellated caecal stage can be transmitted directly by the faecaloral route (Levine, 1985; Hu and McDougald, 2003; McDougald and Fuller, 2005; Liebhart and Hess, 2009) which is thought to occur mostly in turkeys (McDougald, 2005). The second route of infection involves the helminth $H$. gallinarum.

In the event of a co-infection between Histomonas and $H$. gallinarum, Histomonas takes advantage of $H$. gallinarum to improve its survival in the external environment. In the caeca, Histomonas trophozoites are ingested by $H$. gallinarum. Histomonas then travels to the reproductive organs of the helminth. In the female worm, Histomonas enters the ovaries and eventually penetrates the undeveloped oocytes. The helminth ova containing Histomonas become embryonated, and are shed by the female worm into the caeca where they are eventually passed in the hosts faeces (Lee, 1969b; Ruff et al. 1970). Heterakis ova harbouring Histomonas are able to survive in the soil for up to 2 years (Levine, 1985) (Fig. 5). The protozoa are liberated when the helminth ova are ingested by an appropriate host and hatch, releasing both immature worms and the protozoa. In the soil, Heterakis ova containing Histomonas may also be ingested by the common earthworm and still remain infective for both Histomonas and Heterakis (Lund et al.1966; Kemp and Franson, 1975). A gallinaceous bird can become infected with Histomonas by eating an earthworm that has ingested Heterakis ova containing Histomonas (Fig. 5). The earthworm is thought to play an important role in the long-term survival of Histomonas in the soil (Levine, 1985). Several studies exist which describe the relationship between Histomonas and H. gallinarum in greater detail (Lund and Burtner, 1957; Kendall, 1959; Gibbs, 1962; Lee, 1969a; Ruff et al. 1970; Lee, 1971; Lund and Chute, 1973). While it is generally 


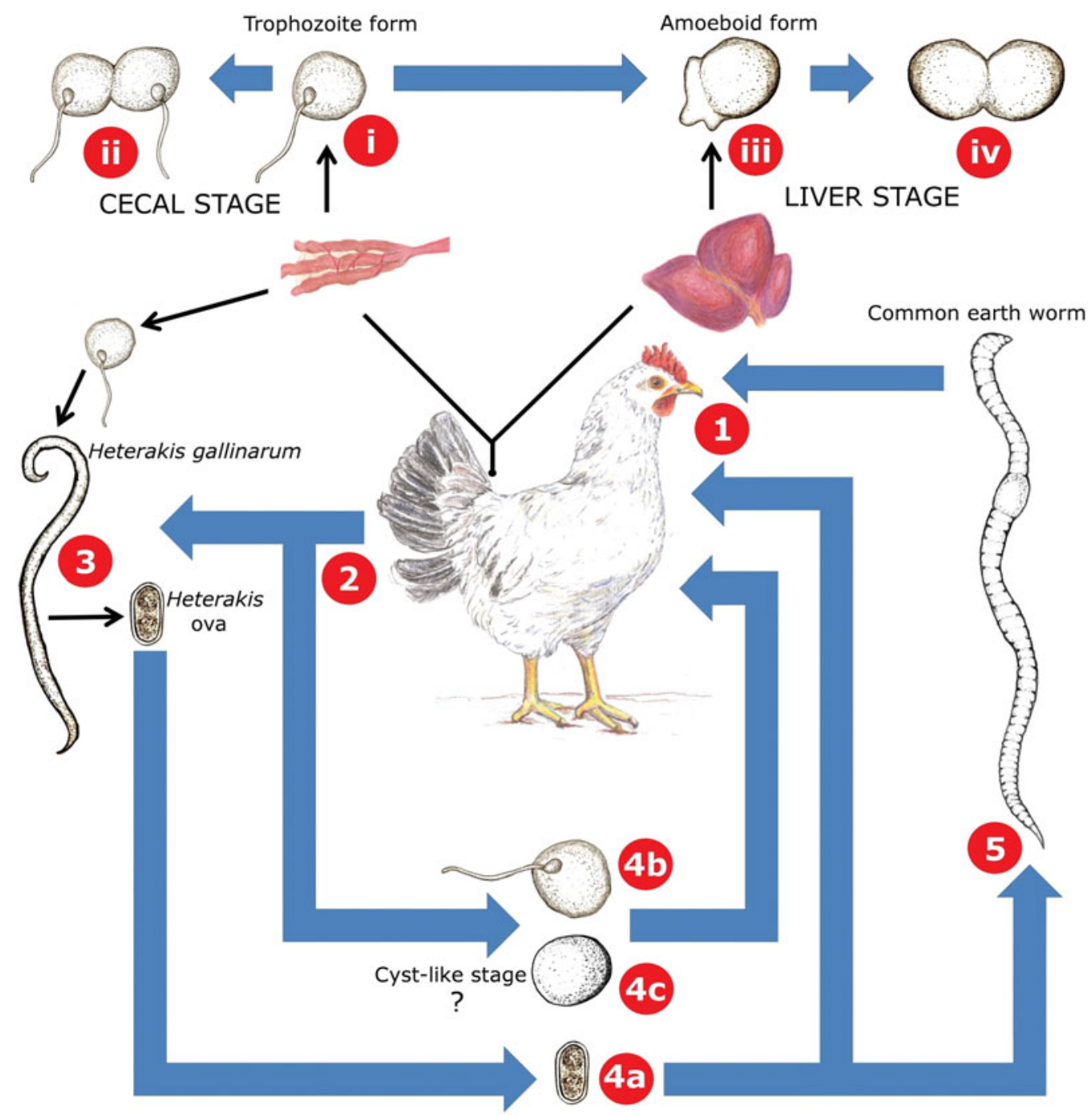

Fig. 5. The life cycle of Histomonas meleagridis. Histomonas trophozoites are ingested from the external environment in various forms by a gallinaceous bird (1). The flagellated trophozoite form of Histomonas travels to the caeca (i) where it multiplies by longitudinal binary fission (ii). Infections with Histomonas usually result in lesions on the caecal wall accompanied by a yellowish diarrhoea. Eventually, Histomonas trophozoites penetrate the caecal mucosa and travel to the liver, where they take on an amoeboid form (iii). The amoeboid form also multiplies by binary fission (iv). The damage caused to liver tissues during the invasive liver stage is often so severe that death will ensue. Histomonas organisms in various forms are then passed in the host's faeces (2) and contaminate food and water sources of other gallinaceous birds. In the event of a Heterakis/Histomonas coinfection, Histomonas trophozoites are ingested by a female Heterakis worm and invade its ovaries. Once in the Heterakis ovaries, Histomonas can then penetrate the developing Heterakis ova (3). These ova are then shed into the host's caeca by the female worm and are eventually passed in the host's faeces. Histomonas can remain viable outside the host within these ova for up to 2 years (4a). Alternatively, free flagellated trophozoites of Histomonas which were shed in the faeces may be directly ingested by a new host resulting in a Histomonas infection (4b). Recently, cyst-like structures of Histomonas have been described (4c) which could represent a newly discovered transmissible stage. However, the infectivity of these cyst-like structures is yet to be demonstrated. In the soil, Heterakis ova containing Histomonas organisms (4a) may also be ingested by the common earth worm (5) which may then be consumed by a gallinaceous bird, resulting in a Histomonas infection. Earthworms are believed to play a significant role in the survival of Histomonas organisms in the soil.

accepted that a cyst stage does not exist for Histomonas, some researchers report the formation of cyst-like structures in vitro which may represent another transmissible stage of Histomonas (Munsch et al. 2009a) (Fig. 5).

After an incubation period of 15-21 days, infected birds become weak and drowsy in appearance (Levine, 1985). This is accompanied by the appearance of a yellowish diarrhoea and ulcerative lesions in the caeca and liver (Huber et al. 2006). Other tissues such as the kidneys and lungs may also be involved (Levine, 1985). In turkey flocks, the mortality rate approaches $100 \%$ in some cases, while in chicken flocks the mortality rate approaches $10-20 \%$ though with high morbidity (McDougald, 2005). Interestingly, experiments involving gnotobiotic birds indicate that in the absence of certain bacteria Histomonas loses its pathogenicity (McDougald, 2005). 
Parahistomonas wenrichi [synonym: Histomonas wenrichi (Mantini et al. 2009)] is similar to Histomonas in terms of its life cycle and biology. Like Histomonas, Parahistomonas is spherical though is approximately 1.5 times larger than Histomonas (Levine, 1985). Parahistomonas possesses 4 flagella as opposed to Histomonas' single flagellum though its movement and feeding are mostly dependent on its pseudopodia. Unlike Histomonas, Parahistomonas is nonpathogenic (Lund, 1963). Parahistomonas' preferred host range also includes gallinaceous birds such as turkeys, chickens and pheasants (Lund, 1963; Levine, 1985). Parahistomonas infections can also be transmitted in the ova of $H$.gallinarum (Lund, 1968, 1971).

\section{Pseudocyst forms and cyst-like structures in Trichomonads}

Under stress conditions several trichomonads enter a pseudocyst stage which is characterized by 'rounding up' of trophozoites and internalization of flagella (Lipman et al. 1999; Granger et al. 2000; Boggild et al. 2002; Ribeiro et al. 2002; Pereira-Neves et al. 2003; Borges et al. 2004; Mariante et al. 2004; Hussein and Atwa, 2008; Pereira-Neves and Benchimol, 2009). During this process, duplication of the nuclei and other cellular structures also occurs resulting in a multinucleated giant cell. When conditions become favourable again, flagellated trophozoites begin to bud from the multinucleated cell (Pereira-Neves and Benchimol, 2009). Pseudocysts of trichomonads are generally described as compact, spherical, multinucleated forms which lack flagella and do not have a true cyst wall (Pereira-Neves et al. 2003).

Pseudocysts were once thought to be degenerative forms though are now known to represent a true stage in the life cycle of some trichomonads. This is because mitosis occurs in the pseudocyst and the process of pseudocyst formation is reversible (Pereira-Neves et al. 2003). Pseudocysts from various trichomonads are also infective to their respective hosts (Friedhoff et al. 1991; Lipman et al. 1999; Pereira-Neves et al. 2003; Pereira-Neves and Benchimol, 2009). Moreover, pseudocysts of $T$. foetus are able to adhere to vaginal epithelial cells more effectively than the trophozoite stage (Mariante et al. 2004; PereiraNeves and Benchimol, 2009). Usually, a small portion of the normal cell population will exist as pseudocysts (Pereira-Neves et al. 2003).

Various stress conditions are known to trigger pseudocyst formation. In cultures of Monocercomonas, the largest number of pseudocyts were produced when cultures were incubated for 4-5 days at pH levels between 5 and 6 (Borges et al. 2007). Fewer pseudocysts were produced by nutrient depletion and incubation at $20^{\circ} \mathrm{C}$ compared to $37^{\circ} \mathrm{C}$ (Borges et al. 2007). Pseudocyst formation can also be induced in Tritrichomonas by the cooling of cultures to just below $16{ }^{\circ} \mathrm{C}$ (Granger et al. 2000). The addition of certain drugs to growth media can also trigger pseudocyst formation (Pereira-Neves and Benchimol, 2009). Mariante et al. (2004) found that incubation of cultures with the drug colchicine, incubation with dimethyl sulfoxide and submitting trophozoites to cycles of temperature oscillation will also induce pseudocyst formation.

Several flagellates are also capable of producing true cysts including members of the genera Retortomonas, Chilomastix and Enteromonas (Levine, 1985) as well as Trichomitus batachorum, Trichomitus sanguisugae and Monocercomonas tipulae (Brugerolle, 1973; PereiraNeves et al. 2003). Interestingly, Mielewczik et al. (2008) also observed cyst-like structures in the faeces of chickens infected with Histomonas. However, these structures could not be attributed to $H$. meleagridis definitively, as all methods of purification failed (Mielewczik et al. 2008). A number of later studies also report the finding of cyst-like stages in cultures of Histomonas (Munsch et al. 2009a,b; Zaragatzki et al. 2010). According to Zaragatzki et al. (2010), formation of these structures can be induced by cultivating Histomonas trophozoites at $\mathrm{pH}$ values between 7 and 8 . However, the infectivity of these structures is yet to be demonstrated.

\section{FURTHER RESEARCH IS REQUIRED}

\section{With respect to animals}

Given the close relationship between humans and primates, it is not surprising that most reports in Table 1 describe the finding of Dientamoeba in monkeys and apes. The evidence for $D$. fragilis infections in gorillas is the most recent and is also well supported. Stark et al. (2008) provided molecular evidence to support their finding of $D$. fragilis in the stools of western lowland gorillas. The recent report by Lankester $e t$ al . (2010) describing an irritable bowel-like illness in a western lowland gorilla also provides support for the findings of Stark et al. (2008). While monkeys and apes may be among the preferred hosts of Dientamoeba, transmission of Dientamoeba between humans and other primates is not a suitable model in parts of the British Isles (Schuster and Jackson, 2009), the USA (Millet et al. 1983a) and the Netherlands (van Gool and Dankert, 1996). This is because Dientamoeba infections are quite common in these places, although human contact with monkeys and apes is virtually non-existent. In these regions, if an animal reservoir is ever identified it is more likely to be a pet or livestock animal, as these are more commonly integrated into those societies.

Dientamoeba has also been reported in the stools of sheep (Noble and Noble, 1952) and swine (Crotti et al. 2007). In regions where human contact with apes is low, these animals are more plausible as reservoirs of Dientamoeba infection. However, Stark 
et al. (2008) found no evidence of Dientamoeba in the stools of 50 sheep and 135 swine. According to Stark et al. (2008), a number of reasons could have attributed to these non-concordant reports. Stark et al. (2008) suggested that the Giemsa stain employed by Crotti et al. (2007) may not have been ideal for visualization of the nuclear structure of $D$. fragilis. Johnson et al. (2004) noted that the fragmented nuclear structure of D. fragilis enables one to distinguish it from organisms such as Endolimax nana which can appear quite similar to Dientamoeba in stained preparations. In the study by Noble and Noble (1952), the staining technique which detected Dientamoeba was not disclosed and no image of Dientamoeba was provided. Stark et al. (2008) did note, however, that differences in farming practices such as caged farming as opposed to free-range style farming or the use of anti-protozoal compounds could have attributed to these conflicting reports. The screening of wild or feral animals for the presence of Dientamoeba may be informative as differences in farming practices do not apply and these animals are unlikely to have been treated with anti-protozoal compounds.

In light of these conflicting reports, the role of swine and sheep in the life cycle of Dientamoeba is uncertain. However, their potential role in the life cycle of Dientamoeba cannot be dismissed. In the study by Stark et al. (2008), a two-step screening approach was employed where stained faecal smears were prepared and those found to contain Dientamoeba were then confirmed with PCR. It is well documented that PCR is more sensitive than light microscopy (Stark et al. 2010a). The intermittent shedding of Dientamoeba trophozoites in humans is also well documented (Stark et al. 2010b). It has been shown that the results of molecular tests are less likely to be influenced by the phenomenon of intermittent shedding (Stark et al. 2010a). As such, the study performed by Stark et al. (2008) could have been improved by testing specimens with PCR or real-time PCR prior to microscopic analysis. The use of molecular tests as the first step in the screening process would have reduced the chances of obtaining false negatives that occur as a result of low parasite loads, intermittent shedding and human error.

While the use of PCR by Stark et al. (2008) provides strong evidence that gorillas are a true host for Dientamoeba, DNA sequence data derived from the SSU rDNA of these gorilla isolates would have been ideal. Similarly, the study by Crotti et al. (2007) could have been greatly improved had their results been supported by molecular evidence in the form of a PCR product and preferably, some DNA sequence data. In order to improve future studies, it is extremely important that researchers utilize molecular techniques to substantiate all findings. Researchers should also obtain sequence data to ensure that their PCR products are specific for Dientamoeba. Sequence data would also be useful for genotyping purposes.
Regarding the experimental infections in humans and animals, these reports are also non-concordant. For instance, Dobell's attempt to infect macaques by rectal inoculation failed (Dobell, 1940). However, 2 reports describe the finding of Dientamoeba in the stools of macaques (Hegner and Chu, 1930; Knowles and DasGupta, 1936). There are several plausible explanations for Dobell's failed attempt to infect macaques. One possibility is that the organisms described in these reports (Hegner and Chu, 1930; Knowles and DasGupta, 1936) were misidentified and macaques are not a true host for Dientamoeba. Another plausible explanation is that Dobell's cultured isolates had been attenuated over time and lost their ability to infect new hosts. However, Dobell's success in infecting 1 of 6 chicks by rectal inoculation is surprising when considering that infections could not be achieved in macaques using the same technique (Dobell, 1940). However, we do not know whether these experiments were carried out at the same time using the same isolate of Dientamoeba. As mentioned previously, Kean and Malloch (1966) also reported some success in their attempt to experimentally infect laboratory rats with Dientamoeba although these experiments are only briefly discussed and appear to be incomplete. Other than the reports by Kean and Malloch (1966) and Dobell (1940), all additional attempts to experimentally infect animals with Dientamoeba have failed.

Taken as a whole, these conflicting reports are difficult to interpret. However, it seems that animal experiments like those performed by Dobell (1940) and Kean and Malloch (1966) must be repeated. The development of a simian model of dientamoebiasis could represent a breakthrough in Dientamoeba research. This would not only allow researchers to explore Dientamoeba's mode of transmission in a controlled manner, but could also be used to determine whether Dientamoeba satisfies Koch's postulates as a cause of gastrointestinal illness.

Given Dobell's success in inducing a transient infection in a chick (Dobell, 1940), the role of poultry in the transmission of Dientamoeba is also worth exploring further. Interestingly, the optimum temperature for growth of Dientamoeba in vitro is $41-42{ }^{\circ} \mathrm{C}$ rather than $37^{\circ} \mathrm{C}$ (Dobell, 1940; Barratt et al. 2010). Therefore, the optimum growth temperature for Dientamoeba is closer to the body temperature of birds rather than humans. Given that Dientamoeba's closest relative is a poultry pathogen; it is plausible that poultry could be involved in Dientamoeba's transmission.

\section{With respect to helminths}

While Ockert claimed to have infected himself with Dientamoeba using the ova of $E$. vermicularis, this is difficult to substantiate without the aid of molecular or electron-microscopic evidence. Ideally, 
if structures resembling Dientamoeba trophozoites are observed in the ova of a helminth, electron microscopic images of these Dientamoeba-like bodies should be taken and compared to those produced by Camp et al. (1974) and Silard et al. (1984). Such evidence would provide strong support for Ockert's claims. Furthermore, without molecular evidence it is difficult to ascertain whether Ockert's Dientamoeba was of the same genotype as the Dientamoeba in the child from which he had infected himself. Given Ockert's frequent handling and processing of stool specimens containing Dientamoeba, it is possible that he infected himself from another source. The most compelling support for the lack of an association between Enterobius and Dientamoeba is the molecular evidence provided by Menghi et al. (2005) who failed to amplify a Dientamoeba-specific PCR product from Enterobius ova derived from a patient who was also infected with Dientamoeba.

While associations may have been observed between Enterobius and Dientamoeba, similar associations between Dientamoeba and other enteric parasites have also been reported (Johnson et al. 2004). Ayadi and Bahri (1999) noted, that Dientamoeba infections were most often associated with Blastocystis. Stark et al. (2005) also found that Dientamoeba infections were most often associated with Blastocystis. Ozcakir et al. (2007) noted that Blastocystis was more frequently detected alongside $D$. fragilis compared to any other enteric protozoa. Stensvold et al. (2009) found that 34.8\% $(n=32)$ of patients with Blastocystis infection were also infected with $D$. fragilis. As such, it is possible that the associations between Dientamoeba and Enterobius described by Yang and Scholten (1977) and Girginkardesler et al. (2008) may represent nothing more than a shared mode of transmission between these organisms.

The report by Sukanahaketu (1977) provides support for the existence of a relationship between Dientamoeba and Ascaris. While the images presented by Sukanahaketu (1977) are interesting, the finding of Dientamoeba-like structures in the ova of Ascaris is not supported by the occurrence of Dientamoeba infections in non-tropical, western countries where Ascaris infections are very uncommon (Walker et al. 1985; Stensvold et al. 2007; Schuster and Jackson, 2009). Therefore, the transmission of Dientamoeba by means of an Ascaris vector is not a suitable model for Dientamoeba transmission in these regions.

Given the molecular evidence described by Menghi et al. (2005) and the lack of an association between pinworm and Dientamoeba observed in several studies, the role of Enterobius in the life cycle of Dientamoeba remains controversial. Despite this, Ockert's hypotheses regarding the role of Enterobius in the transmission of Dientamoeba should not be disregarded. Johnson et al. (2004) noted that spontaneous remissions of Enterobius infection do occur and it is often not clear in some reports whether patients were tested correctly for the presence of Enterobius. Clearly, if future researchers observe Dientamoeba-like bodies in the ova of a helminth, support for these findings in the form of molecular evidence and electron microscopic images is essential.

\section{With respect to Dientamoeba's relatives}

Given the existence of pseudocysts in T. foetus and the recent evidence for cyst-like structures in Histomonas, it is plausible that similar structures could exist for Dientamoeba. Pseudocyst formation as observed in some trichomonads is easily noted by the invagination of the flagella. Unfortunately, such an event cannot be observed in Dientamoeba because it completely lacks flagella. Furthermore, another feature of pseudocysts in trichomonads is that they are multinucleated (Pereira-Neves et al. 2003; Borges et al.2007). Dientamoeba trophozoites are often multinucleated (Johnson et al. 2004) which would also make it difficult to identify pseudocyst forms in Dientamoeba if they did exist.

To explore the possible existence of a pseudocyst stage in Dientamoeba, the experiments performed by Borges et al. (2007), Pereira-Neves et al. (2009), and Mariante et al. (2004) should be repeated for Dientamoeba. Staining Dientamoeba cells with a specific nuclear stain such as DAPI (Noel et al. 2003; Al-Adhami et al. 2007; Taniwaki et al. 2007) would be helpful in these experiments to identify if any changes occur with respect to the number of nuclei in the cells. It is possible that the Dientamoeba cells occasionally reported to contain 4 or more nuclei (Johnson et al. 2004) could represent a pseudocyst form.

As previously mentioned, several flagellates are also capable of producing true cysts (Brugerolle, 1973; Levine, 1985; Pereira-Neves et al. 2003). Therefore, the possibility that a cyst stage could exist for Dientamoeba should not be dismissed. Given the recent discovery of the cyst stage of Blastocystis in 1991 (Stenzel and Boreham, 1991) it is not impossible that a cyst stage for Dientamoeba is yet to be discovered. Moreover, given the recent reports of a cystlike stage for Histomonas (Mielewczik et al. 2008; Munsch et al. 2009a; Zaragatzki et al. 2010), the existence of a similar stage for Dientamoeba is plausible. Should a cyst-like stage be identified for Dientamoeba, the findings must be substantiated through the use of electron microscopic comparisons of these structures to the cyst stages of other trichomonads. Molecular support for such a substantial claim is also important. Finally, the infectivity of these structures must also be demonstrated.

When examining the life cycles of Histomonas and Tritrichomonas, one major similarity becomes apparent. That is that these organisms can be transmitted 
directly between their preferred hosts. As such, the trophozoite stage of Dientamoeba may still be the only stage in its life cycle. It was noted previously that $T$. foetus does not possess a cyst stage and remains culturally viable for up to $6 \mathrm{~h}$ after being excreted in the faeces of cats (Hale et al. 2009). Also, direct bird-to-bird transmission of the trophozoite stage of Histomonas in the absence of a Heterakis vector has been well documented (Levine, 1985; $\mathrm{Hu}$ and McDougald, 2003; McDougald and Fuller, 2005; Liebhart and Hess, 2009). Given that Dientamoeba trophozoites are reported to remain viable for up to 8 times longer than those of $T$. foetus (Kean and Malloch, 1966; Stark et al. 2010a), it is not unreasonable to suggest that Dientamoeba trophozoites may be transmitted directly from human to human. Nevertheless, if trophozoites are the transmissible form, it is uncertain as to why Dobell (1940) was unable to infect himself and 2 macaques orally with cultured trophozoites. This could be the result of attenuation of the trophozoites after long-term culture though, without information on the passage number and source of Dobell's cultures it is difficult to speculate. The development of an animal model for dientamoebiasis would greatly assist in addressing these problems.

\section{CONCLUDING REMARKS}

Dientamoeba fragilis is an inhabitant of the human gastrointestinal tract for which the mode of transmission is unknown. As no cyst stage has been identified for Dientamoeba (at the time of writing), the trophozoite form is generally accepted as the only stage in its life cycle. However, the fragile nature of Dientamoeba trophozoites once passed from their host implies that direct human-to-human transmission of the trophozoite form seems unlikely. Numerous investigations have been carried out in an attempt to better understand Dientamoeba's life cycle. Despite these efforts our knowledge of this organism has progressed very little. Clearly, more research is required.

While several reports attempt to address the lack of knowledge on this organism, most are lacking in one crucial component; that is evidence in the form of molecular and/or electron microscopic data. It is imperative that claims relating to the life cycle and transmission of Dientamoeba, are substantiated using these techniques for several reasons. As discussed previously, light microscopic analysis is less sensitive and less specific than PCR. Moreover, light microscopy introduces a greater element of human error when compared to molecular techniques. Sequencing of PCR products allows researchers to accurately determine the presence and/or identity of an organism almost beyond a doubt. Electron microscopy is a powerful tool which allows detailed observations to be made on the intracellular architecture of cells which cannot be matched by light microscopy. It has become apparent that if modern techniques such as PCR, DNA sequencing and electron microscopy are not employed to substantiate findings related to the life cycle of Dientamoeba, it is unlikely that they will be accepted by the broader scientific community.

Unfortunately, our lack of an animal model for this organism is also a short coming which must be addressed. The lack of an animal model for Dientamoeba infection hampers our ability to study its biology, mode of transmission and mechanisms of pathogenicity in a well-controlled manner. Such a model may also help in the fulfilment of Koch's postulates for Dientamoeba.

Dientamoeba has recently emerged as a significant cause of gastrointestinal illness in humans (Girginkardesler et al. 2003; Johnson et al. 2004; Lagace-Wiens et al. 2006; Crotti and D'Annibale, 2007; Stark et al. 2009a, 2010b). As such, the lack of research being performed on this organism limits our capacity to introduce appropriate control methods. As the importance of this neglected parasite becomes increasingly recognized, the need for more research on this organism becomes more apparent.

The life cycles of Dientamoeba's closest relatives are generally well characterized and it is postulated that these organisms could provide some clues in relation to Dientamoeba's mode of transmission. Based on the life cycles of Histomonas and Tritrichomonas, it is plausible that helminths and/or animals could play a role in the transmission of Dientamoeba. Moreover, the recent reports of pseudocysts and cyst-like structures in some trichomonads imply that similar structures could exist for Dientamoeba. Direct human-to-human transmission of Dientamoeba is also plausible given that Histomonas and Tritrichomonas can be transmitted between their respective hosts in this way. As none of these theories has been sufficiently proven or disproven, none can be dismissed at this stage.

Unfortunately, our lack of knowledge on the life cycle of Dientamoeba makes prevention and control of infections extremely difficult. Moreover, the fact that Koch's postulates have not yet been fulfilled for this organism means that some still consider its pathogenicity as a matter of question. Ultimately, it is essential that more research is carried out on Dientamoeba to better understand the life cycle and biology of this neglected albeit important organism.

\section{REFERENCES}

Agnew, D. W., Munson, L., Cobo, E. R., Olesen, D., Corbeil, L. B. and Bondurant, R.H. (2008). Comparative histopathology and antibody responses of non-Tritrichomonas foetus trichomonad and Tritrichomonas foetus genital infections in virgin heifers. Veterinary Parasitology 151, 170-180.

Al-Adhami, B. H., Nichols, R. A., Kusel, J. R., O'grady, J. and Smith, H. V. (2007). Detection of UV-induced thymine dimers in individual Cryptosporidium parvum and Cryptosporidium hominis oocysts by immunofluorescence microscopy. Applied Environmental Microbiology 73, 947-955 
Ayadi, A. and Bahri, I. (1999). [Dientamoeba fragilis: pathogenic flagellate?]. Bulletin de la Société de Pathologie Exotique 92, 299-301.

Barratt, J. L., Banik, G. R., Harkness, J., Marriott, D., Ellis, J. T. and Stark, D. (2010). Newly defined conditions for the in vitro cultivation and cryopreservation of Dientamoeba fragilis: new techniques set to fast track molecular studies on this organism. Parasitology 137, 1867-1878.

Bleyen, N., De Gussem, K., Pham, A. D., Ons, E., Van Gerven, N. and Goddeeris, B. M. (2009). Non-curative, but prophylactic effects of paromomycin in Histomonas meleagridis-infected turkeys and its effect on performance in non-infected turkeys. Veterinary Parasitology 165, 248-255 Boggild, A. K., Sundermann, C. A. and Estridge, B. H. (2002) Localization of post-translationally modified alpha-tubulin and pseudocys formation in tritrichomonads. Parasitology Research 88, 468-474.

Bondurant, R. H., Gajadhar, A., Campero, C. M., Johnson, E., Lun, Z.-R., Nordhausen, R. W., Hoosear, K. A. V., Villanueva, M. R. and Walker, R. L. (1999). Preliminary characterization of a Tritrichomona foetus-like protozoan isolated from preputial smegma of virgin bulls. Bovine Practitioner 33, 124-127.

Borges, F. P., Gottardi, B., Stuepp, C., Larré, A. B., Vieira, P. D. B. Tasca, T. and Carli, G.A.D. (2007). Morphological aspects of Monocercomonas sp. and investigation on probable pseudocysts occurrence. Parasitology Research 101, 1503-1509.

Borges, F. P., Wiltuschnig, R. C., Tasca, T. and De Carli, G. A. (2004) Scanning electron microscopy study of Tritrichomonas augusta. Parasitology Research 94, 158-161.

Brug, S. L. (1938). Observations on Dientamoeba fragilis. Annals of Tropical Medicine and Parasitology 30, 441-452.

Brugerolle, G. (1973). Sur l'existence de vrais kystes ches les Trichomonadines intestinalis. Ultrastructure des kystes de Trichomitus batrachorum Perty 1852, Trichomitus sanguisugae Alexeieff 1911, et Monocercomonas tipulae Mackinnon 1910. Comptes rendus hebdomadaires des séances de l'Académie des sciences. Série D: Sciences naturelles 277, 2193-2196.

Bruijnesteijn Van Coppenraet, L.E., Wallinga, J. A., Ruijs, G. J. Bruins, M. J. and Verweij, J. J. (2009). Parasitological diagnosis combining an internally controlled real-time PCR assay for the detection of four protozoa in stool samples with a testing algorithm for microscopy. Clinical Microbiology and Infection 15, 869-874.

Burrows, R. B. and Swerdlow, M. A. (1956). Enterobius vermicularis as a probable vector of Dientamoeba fragilis. The American Fournal of Tropical Medicine and Hygiene 5, 258-265.

Butler, W. P. (1996). Dientamoeba fragilis. An unusual intestinal pathogen. Digestive Diseases and Sciences 41, 1811-1813.

Camp, R. R., Mattern, C. F. and Honigberg, B. M. (1974). Study of Dientamoeba fragilis Jepps \& Dobell. I. Electronmicroscopic observations of the binucleate stages. II. Taxonomic position and revision of the genus. The Fournal of Protozoology 21, 69-82

Campero, C. M., Rodriguez Dubra, C., Bolondi, A., Cacciato, C. Cobo, E., Perez, S., Odeon, A., Cipolla, A. and Bondurant, R. H. (2003) Two-step (culture and PCR) diagnostic approach for differentiation of non$T$. foetus trichomonads from genitalia of virgin beef bulls in Argentina. Veterinary Parasitology 112, 167-175.

Cobo, E. R., Campero, C. M., Mariante, R. M. and Benchimol, M. (2003). Ultrastructural study of a tetratrichomonad species isolated from prepucial smegma of virgin bulls. Veterinary Parasitology 117, 195-211. Cobo, E. R., Cano, D. and Campero, C. M. (2001). Experimental infection with Tritrichomonas suis in heifers. Veterinary Parasitology $\mathbf{9 9}$ $73-78$

Cobo, E. R., Canton, G., Morrell, E., Cano, D. and Campero, C. M (2004). Failure to establish infection with Tetratrichomonas sp. in the reproductive tracts of heifers and bulls. Veterinary Parasitology 120, 145-150.

Cobo, E. R., Corbeil, L. B., Agnew, D. W., Vanhoosear, K., Friend, A. Olesen, D. R. and Bondurant, R. H. (2007). Tetratrichomonas spp. and Pentatrichomonas hominis are not persistently detectable after intravaginal inoculation of estrous heifers. Veterinary Parasitology 150, 18-26.

Corbeil, L. B., Campero, C. M., Van Hoosear, K. and Bondurant, R. H. (2008). Detection of trichomonad species in the reproductive tracts of breeding and virgin bulls. Veterinary Parasitology 154, 226-232.

Crotti, D. and D'annibale, M. L. (2007). [Role of Dientamoeba fragilis in human bowel infections]. Le Infezioni in Medicina 15, 30-39.

Crotti, D., Sensi, M., Crotti, S., Grelloni, V. and Manuali, E. (2007) Dientamoeba fragilis in swine population: a preliminary investigation. Veterinary Parasitology 145, 349-351.

Cuffari, C., Oligny, L. and Seidman, E. G. (1998). Dientamoeba fragilis masquerading as allergic colitis. Fournal of Pediatric Gastroenterology and Nutrition 26, 16-20.

Culberson, D. E., Pindak, F. F., Gardner, W. A. and Honigberg, B. M (1986). Tritrichomonas mobilensis n. sp. (Zoomastigophorea:
Trichomonadida) from the Bolivian squirrel monkey Saimiri boliviensis boliviensis. The fournal of Protozoology 33, 301-304.

Dobell, C. (1940). Researches on intestinal protozoa in monkeys and man. X. The life history of Dientamoeba fragilis: Observations, experiments and speculations. Parasitology 32, 417-461.

Dufernez, F., Walker, R. L., Noel, C., Caby, S., Mantini, C., DelgadoViscogliosi, P., Ohkuma, M., Kudo, T., Capron, M., Pierce, R. J., Villanueva, M. R. and Viscogliosi, E. (2007). Morphological and molecular identification of non-Tritrichomonas foetus trichomonad protozoa from the bovine preputial cavity. The Fournal of Eukaryotic Microbiology 54, 161-168.

Felleisen, R. S. (1997). Comparative sequence analysis of 5.8S rRNA genes and internal transcribed spacer (ITS) regions of trichomonadid protozoa. Parasitology 115, 111-119.

Felleisen, R. S., Lambelet, N., Bachmann, P., Nicolet, J., Muller, N. and Gottstein, B. (1998). Detection of Tritrichomonas foetus by PCR and DNA enzyme immunoassay based on rRNA gene unit sequences. Fournal of Clinical Microbiology 36, 513-519.

Friedhoff, K. T., Kuhnigk, C. and Muller, I. (1991). Experimental infections in chickens with Chilomastix gallinarum, Tetratrichomonas gallinarum, and Tritrichomonas eberthi. Parasitology Research 77, 329-334.

Gerbod, D., Edgcomb, V.P., Noel, C., Zenner, L., Wintjens, R., Delgado-Viscogliosi, P., Holder, M.E., Sogin, M. L. and Viscogliosi, E. (2001). Phylogenetic position of the trichomonad parasite of turkeys, Histomonas meleagridis (Smith) Tyzzer, inferred from small subunit rRNA sequence. The Fournal of Eukaryotic Microbiology 48, 498-504. Gerbod, D., Noel, C., Dolan, M. F., Edgcomb, V.P., Kitade, O., Noda, S., Dufernez, F., Ohkuma, M., Kudo, T., Capron, M., Sogin, M. L. and Viscogliosi, E. (2002). Molecular phylogeny of parabasalids inferred from small subunit rRNA sequences, with emphasis on the Devescovinidae and Calonymphidae (Trichomonadea). Molecular Phylogenetics and Evolution 25, 545-556.

Gibbs, B. J. (1962). The occurrence of the protozoan parasite Histomonas meleagridis in the adults and eggs of the cecal worm Heterakis gallinae. The Fournal of Protozoology 9, 288-293.

Girginkardesler, N., Coskun, S., Cuneyt Balcioglu, I., Ertan, P. and Ok, U.Z. (2003). Dientamoeba fragilis, a neglected cause of diarrhea, successfully treated with secnidazole. Clinical Microbiology and Infection $\mathbf{9}$, 110-113.

Girginkardesler, N., Kurt, O., Kilimcioglu, A. A. and Ok, U. Z. (2008) Transmission of Dientamoeba fragilis: evaluation of the role of Enterobius vermicularis. Parasitology International 57, 72-75.

Gookin, J. L., Birkenheuer, A. J., St John, V., Spector, M. and Levy, M. G. (2005). Molecular characterization of trichomonads from feces of dogs with diarrhea. The Fournal of Parasitology 91, 939-943. Gookin, J. L., Breitschwerdt, E. B., Levy, M. G., Gager, R. B. and Benrud, J. G. (1999). Diarrhea associated with trichomonosis in cats. Fournal of the American Veterinary Medical Association 215, $1450-1454$

Granger, B. L., Warwood, S. J., Benchimol, M. and De Souza, W. (2000). Transient invagination of flagella by Tritrichomonas foetus. Parasitology Research 86, 699-709.

Greenway, D. (1928). Dientamoeba fragilis en la Argentina. Archivos Argentinos de Enfermedades del Aparato Digestivo 3, 897.

Hale, S., Norris, J. M. and Slapeta, J. (2009). Prolonged resilience of Tritrichomonas foetus in cat faeces at ambient temperature. Veterinary Parasitology 166, 60-65.

Hayes, D. C., Anderson, R. R. and Walker, R. L. (2003). Identification of trichomonadid protozoa from the bovine preputial cavity by polymerase chain reaction and restriction fragment length polymorphism typing. Fournal of Veterinary Diagnostic Investigation 15, 390-394.

Hegner, R. and Chu, H. J. (1930). A comparative study of the intestinal protozoa of wild monkeys and man. American Fournal of Epidemiology 12, 62-108.

Holliday, M., Deni, D. and Gunn-Moore, D. A. (2009). Tritrichomonas foetus infection in cats with diarrhoea in a rescue colony in Italy. Fournal of Feline Medicine and Surgery 11, 131-134.

Hu, J. and McDougald, L. R. (2003). Direct lateral transmission of Histomonas meleagridis in turkeys. Avian Diseases 47, 489-492.

Huber, K., Reynaud, M. C., Callait, M.P. and Zenner, L. (2006). Histomonas meleagridis in turkeys: dissemination kinetics in host tissues after cloacal infection. Poultry Science 85, 1008-1014.

Huby-Chilton, F., Scandrett, B. W., Chilton, N. B. and Gajadhar, A. A. (2009). Detection and identification of Tetratrichomonas in a preputial wash from a bull by PCR and SSCP. Veterinary Parasitology 23, 3-4

Hussein, E. M. and Atwa, M. M. (2008). Infectivity of Trichomonas vaginalis pseudocysts inoculated intra-vaginally in mice. Fournal of the Egyptian Society of Parasitology 38, 749-762. 
Inpankaew, T., Traub, R., Thompson, R. C. and Sukthana, Y. (2007). Canine parasitic zoonoses in Bangkok temples. The Southeast Asian fournal of Tropical Medicine and Public Health 38, 247-255.

Jepps, M. W. and Dobell, C. (1918). Dientamoeba fragilis n.g., n. sp.: a new intestinal amoeba from man. Parasitology 10, 352-367.

Johnson, E. H., Windsor, J. J. and Clark, C. G. (2004). Emerging from obscurity: biological, clinical, and diagnostic aspects of Dientamoeba fragilis. Clinical Microbiology Reviews 17, 553-570.

Kean, B.H. and Malloch, C.L. (1966). The neglected ameba: Dientamoeba fragilis. A report of 100 "pure" infections. The American Fournal of Digestive Diseases 11, 735-746.

Kemp, R. L. and Franson, J. C. (1975). Transmission of Histomonas meleagridis to domestic fowl by means of earthworms recovered from pheasant yard soil. Avian Diseases 19, 741-744.

Kendall, S. B. (1959). The occurrence of Histomonas meleagridis in Heterakis gallinae. Parasitology 49, 169-172.

Kleina, P., Bettim-Bandinelli, J., Bonatto, S. L., Benchimol, M. and Bogo, M. R. (2004). Molecular phylogeny of Trichomonadidae family inferred from ITS-1, 5.8S rRNA and ITS-2 sequences. International Fournal for Parasitology 34, 963-970.

Knoll, E. W. and Howell, K. M. (1945). Studies on Dientamoeba fragilis: its incidence and possible pathogenicity. American fournal of Clincal Pathology 15, 178-183.

Knowles, R. and DasGupta, B. M. (1936). Some observations on the intestinal protozoa of Macaques. Indian Fournal of Medical Research 24, 547-556

Kofoid, C. A. (1923). Amoeba and Man, University of California Press, Berkeley, CA, USA.

Lagace-Wiens, P.R., Vancaeseele, P. G. and Koschik, C. (2006). Dientamoeba fragilis: an emerging role in intestinal disease. Canadian Medical Association fournal 175, 468-469.

Lankester, F., Kiyang, J. A., Bailey, W. and Unwin, S. (2010) Dientamoeba fragilis: initial evidence of pathogenicity in the Western Lowland Gorilla (Gorilla gorilla gorilla). Fournal of Zoo and Wildlife Medicine 41, 350-352.

Leber1, M., Hess, M. and Bilic, I. (2009). Histomonas meleagridis possesses three alpha-actinins immunogenic to its hosts. Molecular and Biochemical Parasitology 169, 101-107.

Lee, D. L. (1969a). Histomonas in the bird and in the nematode Heterakis. Transactions of the Royal Society of Tropical Medicine $\sigma^{\circ}$ Hygiene $\mathbf{6 3}$, 427-428

Lee, D. L. (1969b). The structure and development of Histomonas meleagridis (Mastigamoebidae: Protozoa) in the female reproductive tract of its intermediate host, Heterakis gallinarum (Nematoda). Parasitology 59, $877-884$

Lee, D. L. (1971). The structure and development of the protozoon Histomonas meleagridis in the male reproductive tract of its intermediate host, Heterakis gallinarum (Nematoda). Parasitology 63, 439-445.

Levine, N. D. (1985). Veterinary Protozoology. Iowa State University Press, Ames, IO, USA.

Levy, M. G., Gookin, J. L., Poore, M., Birkenheuer, A. J., Dykstra, M. J. and Litaker, R. W. (2003). Tritrichomonas foetus and not Pentatrichomonas hominis is the etiologic agent of feline trichomonal diarrhea. The Fournal of Parasitology 89, 99-104.

Liebhart, D. and Hess, M. (2009). Oral infection of turkeys with in vitrocultured Histomonas meleagridis results in high mortality. Avian Pathology 38, 223-227.

Lipman, N. S., Lampen, N. and Nguyen, H. T. (1999). Identification of pseudocysts of Tritrichomonas muris in Armenian hamsters and their transmission to mice. Laboratory Animal Science 49, 313-315.

Lun, Z. R., Chen, X. G., Zhu, X. Q., Li, X. R. and Xie, M. Q. (2005). Are Tritrichomonas foetus and Tritrichomonas suis synonyms? Trends in Parasitology 21, 122-125.

Lund, E. E. (1963). Histomonas wenrichi N. Sp. (Mastigophora: Mastigamoebidae), a nonpathogenic parasite of gallinaceous Birds. The Fournal of Protozoology 10, 401-404.

Lund, E. E. (1968). Acquisition and liberation of Histomonas wenrichi by Heterakis gallinarum. Experimental Parasitology 22, 62-67.

Lund, E.E. (1971). Histomonas meleagridis and H. wenrichi: time of acquisition by Heterakis gallinarum. Experimental Parasitology 29, 59-65.

Lund, E. E. and Burtner, R. H. Jr. (1957). Infectivity of Heterakis gallinae eggs with Histomonas meleagridis. Experimental Parasitology 6, 189-193.

Lund, E. E. and Chute, A. M. (1973). Means of acquisition of Histomonas meleagridis by eggs of Heterakis gallinarum. Parasitology 66, 335-342.

Lund, E. E., Wehr, E. E. and Elli, D. J. (1966). Earthworm transmission of Heterakis and Histomonas to turkeys and chickens. The Fournal of Parasitology 52, 899-902.
Mantini, C., Dalia-Cornette, J., Noda, S., Van Der Heijden, H. M., Capron, M., Dei-Cas, E., Landman, W. J., Ohkuma, M. and Viscogliosi, E. (2009). Molecular identification and phylogenetic relationships of trichomonad isolates of galliform birds inferred from nuclear small subunit rRNA gene sequences. Parasitology Research 106, 163-170.

Mardones, F.O., Perez, A.M., Martinez, A. and Carpenter, T.E. (2008). Risk factors associated with Tritrichomonas foetus infection in beef herds in the Province of Buenos Aires, Argentina. Veterinary Parasitology 153, 231-237

Mariante, R. M., Lopes, L. C. and Benchimol, M. (2004). Tritrichomonas foetus pseudocysts adhere to vaginal epithelial cells in a contact-dependent manner. Parasitology Research 92, 303-312.

McDougald, L. R. (2005). Blackhead disease (histomoniasis) in poultry: a critical review. Avian Diseases 49, 462-476.

McDougald, L. R. and Fuller, L. (2005). Blackhead disease in turkeys: direct transmission of Histomonas meleagridis from bird to bird in a laboratory model. Avian Diseases 49, 328-331.

Menghi, C. I., Makiya, R. and Gatta, C. L. (2005). Dientamoeba fragilis molecular biology techniques for the elucidation of its mode of transmission. Parasitología Latinoamericana, 60, 25-31.

Mielewczik, M., Mehlhorn, H., Al-Quraishy, S., Grabensteiner, E. and Hess, M. (2008). Transmission electron microscopic studies of stages of Histomonas meleagridis from clonal cultures. Parasitology Research 103, $745-750$.

Millet, V., Spencer, M. J., Chapin, M., Stewart, M., Yatabe, J. A., Brewer, T. and Garcia, L.S. (1983a). Dientamoeba fragilis, a protozoan parasite in adult members of a semicommunal group. Digestive Diseases and Sciences 28, 335-339.

Millet, V. E., Spencer, M. J., Chapin, M. R., Garcia, L. S., Yatabe, J. H. and Stewart, M. E. (1983b). Intestinal protozoan infection in a semicommunal group. The American Fournal of Tropical Medicine and Hygiene 32, 54-60.

Mollari, M. and Anzulovic, J. V. (1938). Cultivation and pathogenicity of D. fragilis with a case report. Fournal of Tropical Medicine and Hygiene $\mathbf{4 1}$, 246-247.

Munsch, M., Lotfi, A., Hafez, H.M., Al-Quraishy, S. and Mehlhorn, H. (2009a). Light and transmission electron microscopic studies on trophozoites and cyst-like stages of Histomonas meleagridis from cultures. Parasitology Research 104, 683-689.

Munsch, M., Mehlhorn, H., Al-Quraishy, S., Lotfi, A. R. and Hafez, H. M. (2009b). Molecular biological features of strains of Histomonas meleagridis. Parasitology Research 104, 1137-1140.

Myers, B. J. and Kuntz, R. E. (1968). Intestinal protozoa of the baboon Papio doguera Pucheran, 1856. The Fournal of Protozoology 15, 363-365.

Noble, G. A. and Noble, E. R. (1952). Entamoeba in farm animals. The Fournal of Parasitology 38, 571-595.

Noel, C., Gerbod, D., Delgado-Viscogliosi, P., Fast, N. M., Younes, A. B., Chose, O., Roseto, A., Capron, M. and Viscogliosi, E. (2003). Morphogenesis during division and griseofulvin-induced changes of the microtubular cytoskeleton in the parasitic protist, Trichomonas vaginalis. Parasitology Research 89, 487-494.

Ockert, G. (1972a). [Epidemiology of Dientamoeba fragilis Jepps and Dobell 1918. 1. Spread of the species in child collectives]. Fournal of Hygiene, Epidemiology, Microbiology, and Immunology 16, 213-221.

Ockert, G. (1972b). [Epidemiology of Dientamoeba fragilis Jepps and Dobell, 1918. 2. Attempt at species transfer with Enterobius eggs]. Fournal of Hygiene, Epidemiology, Microbiology, and Immunology 16, 213-221.

Ockert, G. (1975). [Epidemiology of Dientamoeba fragilis Jepps and Dobell, 1918. 3. Further studies on Enterobius transmission through eggs]. Fournal of Hygiene, Epidemiology, Microbiology, and Immunology 19 $17-21$

Ockert, G. and Schmidt, T. (1976). [On the epidemiology of Dientamoeba fragilis Jepps and Dobell 1918. 4th communication: evidence of Dientamoeba fragilis in Enterobius eggs using isoelectric point determination]. Fournal of Hygiene, Epidemiology, Microbiology, and Immunology 20, $76-81$

Ohkuma, M., Iida, T., Ohtoko, K., Yuzawa, H., Noda, S., Viscogliosi, E. and Kudo, T. (2005). Molecular phylogeny of parabasalids inferred from small subunit rRNA sequences, with emphasis on the Hypermastigea. Molecular Phylogenetics and Evolution 35, 646-655.

Oxner, R. B., Paltridge, G.P., Chapman, B.A., Cook, H. B. and Sheppard, P. F. (1987). Dientamoeba fragilis: a bowel pathogen? The New Zealand Medical Fournal 100, 64-65.

Ozcakir, O., Gureser, S., Erguven, S., Yilmaz, Y. A., Topaloglu, R. and Hascelik, G. (2007). Characteristics of Blastocystis hominis infection in a Turkish university hospital. Turkiye Parazitolojii Dergisi 31, $277-282$. 
Pereira-Neves, A. and Benchimol, M. (2009). Tritrichomonas foetus: budding from multinucleated pseudocysts. Protist 160, 536-551.

Pereira-Neves, A., Ribeiro, K. C. and Benchimol, M. (2003). Pseudocysts in trichomonads-new insights. Protist 154, 313-329.

Piekarski, G. (1948). Zur Frage der Cystenbildung bei Dientamoeba fragilis. Zeitschrift für Hygiene und Infektionskrankheiten 127, 496-500.

Powell, F. L., Rothwell, L., Clarkson, M. J. and Kaiser, P. (2009). The turkey, compared to the chicken, fails to mount an effective early immune response to Histomonas meleagridis in the gut. Parasite Immunology 31, 312-327

Pozio, E. (2008). Epidemiology and control prospects of foodborne parasitic zoonoses in the European Union. Parassitologia 50, 17-24.

Rae, D. O. and Crews, J. E. (2006). Tritrichomonas foetus. The Veterinary Clinics of North America. Food Animal Practice 22, 595-611.

Ribeiro, K. C., Pereira-Neves, A. and Benchimol, M. (2002). The mitotic spindle and associated membranes in the closed mitosis of trichomonads. Biology of the Cell 94, 157-172.

Robertson, L. J. (2009). Giardia and Cryptosporidium infections in sheep and goats: a review of the potential for transmission to humans via environmental contamination. Epidemiology and Infection 137, 913-921. Romatowski, J. (2000). Pentatrichomonas hominis infection in four kittens Fournal of the American Veterinary Medical Association 216, 1270-1272. Ruff, M. D., McDougald, L. R. and Hansen, M. F. (1970). Isolation of Histomonas meleagridis from embryonated eggs of Heterakis gallinarum. The Fournal of Protozoology 17, 10-11.

Schlundt, J., Toyofuku, H., Jansen, J. and Herbst, S. A. (2004) Emerging food-borne zoonoses. Revue Scientifique et Technique 23, 513-533. Schuster, H. and Jackson, R. S. (2009). Prevalence of Dientamoeba fragilis among patients consulting complementary medicine practitioners in the British Isles. Fournal of Clinical Pathology 62, 182-184.

Silard, R., Burghelea, B., Panaitescu, D. and Burcos, V. (1984). Ultrastructure of Dientamoeba fragilis: a study of the mononucleated stage. Archives Roumaines de Pathologie Experimentales et de Microbiologie 43, 87-101.

Silard, R., Colea, A., Panaitescu, D., Florescu, P. and Roman, N. (1979). Studies on Dientamoeba fragilis in Romania. I. Dientamoeba fragilis isolated from clinical cases. Problems of diagnosis, incidence, clinical aspects. Archives Roumaines de Pathologie Experimentale et de Microbiologie 38, 359-372.

Smith, H. V., Caccio, S. M., Cook, N., Nichols, R. A. and Tait, A. (2007). Cryptosporidium and Giardia as foodborne zoonoses. Veterinary Parasitology 149, 29-40.

Stark, D., Barratt, J., Ellis, J., Harkness, J. and Marriott, D. (2009a). Repeated Dientamoeba fragilis infections: A case report of two families from Sydney, Australia. Infectious Disease Reports 1, 7-9

Stark, D., Barratt, J., Roberts, T., Marriott, D., Harkness, J. and Ellis, J. (2010a). Comparison of microscopy, two xenic culture techniques, conventional and real-time PCR for the detection of Dientamoeba fragilis in clinical stool samples. European fournal of Clinical Microbiology $\xi$ Infectious Diseases 29, 411-416.

Stark, D., Barratt, J., Roberts, T., Marriott, D., Harkness, J. and Ellis, J. $(2010 b)$. A review of the clinical presentation of dientamoebiasis. The American Fournal of Tropical Medicine and Hygiene 82, 614-619.

Stark, D., Barratt, J. L., Van Hal, S., Marriott, D., Harkness, J. and Ellis, J. T. (2009b). Clinical significance of enteric protozoa in the immunosuppressed human population. Clinical Microbiology Reviews 22, 634-650.

Stark, D., Beebe, N., Marriott, D., Ellis, J. and Harkness, J. (2005). Prospective study of the prevalence, genotyping, and clinical relevance of Dientamoeba fragilis infections in an Australian population. Fournal of Clinical Microbiology 43, 2718-2723.

Stark, D., Phillips, O., Peckett, D., Munro, U., Marriott, D. Harkness, J. and Ellis, J. (2008). Gorillas are a host for Dientamoeba fragilis: an update on the life cycle and host distribution. Veterinary Parasitology 151, 21-26.

Stark, D. J., Beebe, N., Marriott, D., Ellis, J. T. and Harkness, J. (2006) Dientamoebiasis: clinical importance and recent advances. Trends in Parasitology 22, 92-96.

Stensvold, C. R., Arendrup, M. C., Molbak, K. and Nielsen, H. V. (2007). The prevalence of Dientamoeba fragilis in patients with suspected enteroparasitic disease in a metropolitan area in Denmark. Clinical Microbiology and Infection 13, 839-842.

Stensvold, C. R., Lewis, H. C., Hammerum, A. M., Porsbo, L. J. Nielsen, S.S., Olsen, K. E., Arendrup, M.C., Nielsen, H. V. and Molbak, K. (2009). Blastocystis: unravelling potential risk factors and clinical significance of a common but neglected parasite. Epidemiology and Infection 137, 1655-1663.

Stenzel, D. J. and Boreham, P. F. (1991). A cyst-like stage of Blastocystis hominis. International fournal for Parasitology 21, 613-615.

Stockdale, H., Rodning, S., Givens, M., Carpenter, D., Lenz, S., Spencer, J., Dykstra, C., Lindsay, D. and Blagburn, B. (2007). Experimental infection of cattle with a feline isolate of Tritrichomonas foetus. The Fournal of Parasitology 93, 1429-1434.

Stockdale, H.D., Dillon, A. R., Newton, J.C., Bird, R. C., Bondurant, R. H., Deinnocentes, P., Barney, S., Bulter, J., Land, T., Spencer, J. A., Lindsay, D. S. and Blagburn, B. L. (2008). Experimental infection of cats (Felis catus) with Tritrichomonas foetus isolated from cattle. Veterinary Parasitology 154, 156-161.

Stockdale, H. D., Givens, M. D., Dykstra, C. C. and Blagburn, B. L. (2009). Tritrichomonas foetus infections in surveyed pet cats. Veterinary Parasitology 160, 13-17.

Sukanahaketu, S. (1977). The presence of Dientamoeba fragilis in the Ascaris lumbricoides ova: the first report from Thailand. Fournal of The Medical Association of Thailand 60, 256-258.

Tachezy, J., Tachezy, R., Hampl, V., Sedinova, M., Vanacova, S., Vrlik, M., Van Ranst, M., Flegr, J. and Kuldaa, J. (2002). Cattle pathogen Tritrichomonas foetus (Riedmuller, 1928) and pig commensal Tritrichomonas suis (Gruby \& Delafond, 1843) belong to the same species. Fournal of Eukaryotic Microbiology 49, 154-163.

Taniwaki, N. N., Da Silva, C. V., Da Silva, S. and Mortara, R. A. (2007). Distribution of Trypanosoma cruzi stage-specific epitopes in cardiac muscle of Calomys callosus, BALB/c mice, and cultured cells infected with different infective forms. Acta Tropica 103, 14-25.

Tolbert, M. K. and Gookin, J. (2009). Tritrichomonas foetus: a new agent of feline diarrhea. Compendium on Continuing Education for the Practicing Veterinarian 31, 374-381.

Traub, R. J., Inpankaew, T., Reid, S. A., Sutthikornchai, C., Sukthana, Y., Robertson, I. D. and Thompson, R. C. (2009). Transmission cycles of Giardia duodenalis in dogs and humans in Temple communities in Bangkok-a critical evaluation of its prevalence using three diagnostic tests in the field in the absence of a gold standard. Acta Tropica 111, 125-132.

Van Gool, T. and Dankert, J. (1996). [3 emerging protozoal infection in The Netherlands: Cyclospora, Dientamoeba, and Microspora infections]. Nederlands Tijdschrift voor Geneeskunde 140, 155-160.

Vandenberg, O., Peek, R., Souayah, H., Dediste, A., Buset, M., Scheen, R., Retore, P., Zissis, G. and Van Gool, T. (2006). Clinical and microbiological features of dientamoebiasis in patients suspected of suffering from a parasitic gastrointestinal illness: a comparison of Dientamoeba fragilis and Giardia lamblia infections. International Yournal of Infectious Diseases 10, 255-261.

Walker, J. C., Bahr, G. and Ehl, A. S. (1985). Gastrointestinal parasites in Sydney. The Medical Fournal of Australia 143, 480.

Wenrich, D. H. (1936). Studies on Dientamoeba fragilis (protozoa). I. Observations with special reference to nuclear structure. The Fournal of Parasitology 22, 76-83.

Wenrich, D. H. (1944). Studies on Dientamoeba fragilis (Protozoa). IV. Further observations, with an outline of present days knowledge of this species. The Fournal of Parasitology 30, 322-338.

Yang, J. and Scholten, T. (1977). Dientamoeba fragilis: a review with notes on its epidemiology, pathogenicity, mode of transmission, and diagnosis. American Fournal of Tropical Medicine Hygiene 26, 16-22.

Yoshikawa, H., Wu, Z., Nagano, I. and Takahashi, Y. (2003). Molecular comparative studies among Blastocystis isolates obtained from humans and animals. The Fournal of Parasitology 89, 585-594.

Zaragatzki, E., Hess, M., Grabensteiner, E., Abdel-Ghaffar, F. Al-Rasheid, K. A. and Mehlhorn, H. (2010). Light and transmission electron microscopic studies on the encystation of Histomonas meleagridis. Parasitology Research 106, 977-983. 
Reproduced with permission of the copyright owner. Further reproduction prohibited without permission. 


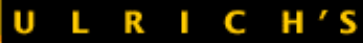
Periodicals Directory"

The globalsourcefor

periodicals information since-1932
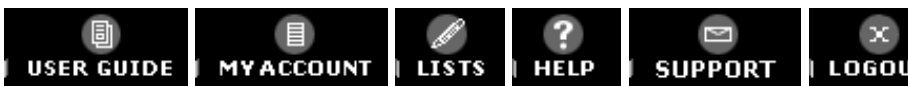

Advanced Search Browse Ulrich's Alert Ulrich's Update

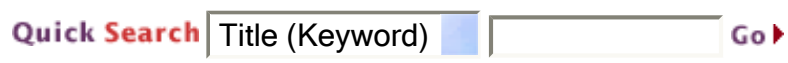

\section{Parasitology (Cambridge)}

¿ BACK TO RESULTS

SEARCH MY LI BRARY'S CATALOG: ISSN Search | Title Search

\begin{tabular}{|c|c|c|c|c|c|}
\hline $\begin{array}{c}\text { Basic } \\
\text { Description }\end{array}$ & \multicolumn{2}{|c|}{$\begin{array}{l}\text { Other Editions/ } \\
\text { Formats }\end{array}$} & $\begin{array}{c}\text { Abstracting } / \\
\text { Indexing } 8 \text { Article } \\
\text { Access }\end{array}$ & $\begin{array}{l}\text { Publisher \& } \\
\text { Ordering } \\
\text { Information }\end{array}$ & $\begin{array}{c}\text { Advertising, Rights, } \\
\text { Demographics }\end{array}$ \\
\hline \multicolumn{6}{|c|}{ G S F F X } \\
\hline \multicolumn{6}{|c|}{ Click highlighted text for a new search on that item. } \\
\hline \multicolumn{2}{|c|}{ Table of Contents: } & \multicolumn{2}{|c|}{$\underline{\text { Click here to view }}$} & & \\
\hline \multicolumn{2}{|l|}{ ISSN: } & \multicolumn{2}{|c|}{$0031-1820$} & & \\
\hline \multicolumn{2}{|l|}{ Title: } & \multicolumn{3}{|c|}{ Parasitology (Cambridge) } & $\nabla$ Additional Title Information \\
\hline \multicolumn{2}{|c|}{ Publishing Body: } & \multicolumn{3}{|c|}{ Cambridge University Press } & \\
\hline \multicolumn{2}{|l|}{ Country: } & \multicolumn{3}{|c|}{ United Kingdom } & \\
\hline \multicolumn{2}{|l|}{ Status: } & \multicolumn{3}{|c|}{ Active } & \\
\hline \multicolumn{2}{|l|}{ Start Year: } & \multicolumn{3}{|c|}{1908} & \\
\hline \multicolumn{2}{|l|}{ Frequency: } & \multicolumn{3}{|c|}{ Monthly (Plus two supplements) } & \\
\hline \multicolumn{2}{|c|}{ Document Type: } & \multicolumn{3}{|c|}{ J ournal; Academic/Scholarly } & \\
\hline \multicolumn{2}{|l|}{ Refereed: } & \multicolumn{3}{|l|}{ Yes } & \\
\hline \multicolumn{2}{|c|}{ Abstracted/ I ndexed: } & \multicolumn{3}{|l|}{ Yes } & \\
\hline \multicolumn{2}{|l|}{ Media: } & \multicolumn{3}{|c|}{ Print } & \\
\hline \multicolumn{2}{|c|}{$\begin{array}{l}\text { Alternate Edition } \\
\text { I SSN: }\end{array}$} & \multicolumn{3}{|c|}{$\underline{1469-8161}$} & \\
\hline \multicolumn{2}{|c|}{ RSS Availability: } & \multicolumn{4}{|c|}{ Click here to view } \\
\hline \multicolumn{2}{|l|}{ Language: } & Text & in English & & \\
\hline Price: & & $\begin{array}{l}\text { GBP } \\
\text { GBP } \\
\text { (Prin } \\
\text { (effe }\end{array}$ & $\begin{array}{l}945, \text { USD } 1,810 \\
990, \text { USD } 1,880 \\
\text { \& Online Eds.) } \\
\text { tive 2009) }\end{array}$ & $\begin{array}{l}\text { scription pe } \\
\text { nbined subs }\end{array}$ & $\begin{array}{l}\text { year to institutions } \\
\text { ription per year to institutions }\end{array}$ \\
\hline Subject: & & $\underline{\text { MED }}$ & CAL SCIENCES - & MMUNICA & E DISEASES \\
\hline Dewey \#: & & 616. & & & \\
\hline LC\#: & & QL7! & & & \\
\hline CODEN: & & PAR & & & \\
\hline Special Fea & es: & Inclu & des Advertising, & ok Reviews & \\
\hline Article I nde & & Inde & & & \\
\hline Editor(s): & & $\mathrm{CAr}$ & ee, R.S. Phillips & & \\
\hline URL: & & $\underline{\text { http }}$ & /journals.cambri & e.org/actior & display| ournal?jid=PAR \\
\hline Description & & $\begin{array}{l}\text { Publ } \\
\text { inclu } \\
\text { topic }\end{array}$ & $\begin{array}{l}\text { hes papers on a } \\
\text { ng biochemical, } \\
\text { with emphasis }\end{array}$ & $\begin{array}{l}\text { spects of } p \\
\text { munologic } \\
\text { parasites }\end{array}$ & $\begin{array}{l}\text { e and applied parasitology, } \\
\text { physiological, and ecological } \\
\text { d their control. }\end{array}$ \\
\hline
\end{tabular}

\section{ADDI TI ONAL TITLE I NFORMATI ON}

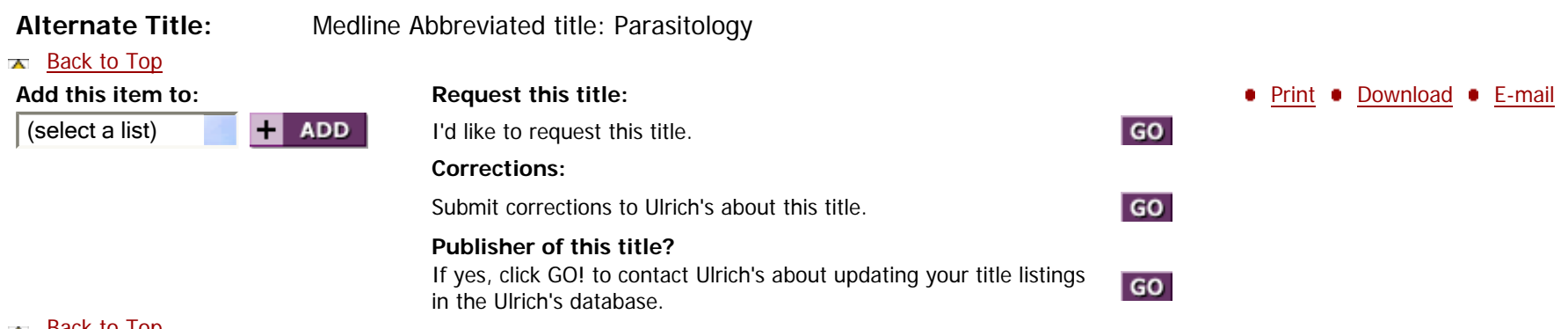

